\title{
Análise das relações entre uso de indicadores de desempenho organizacional e fatores contingenciais: uma investigação em empresas de construção civil da cidade de Recife - PE.
}

\author{
Analysis of the relationship between use \\ of organizational performance indicators \\ and contingency factors: an investigation in \\ construction companies of the city of Recife - PE.
}

\author{
HERIVANNIO TORRES BANDEIRA \\ Ministério Público Federal, Procuradoria Regional da República da $5^{\mathrm{a}}$ Região \\ ALDO LEONARDO CUNHA CALLADO \\ Universidade Federal da Paraíba
}

\section{RESUMO}

Este trabalho teve por objetivo analisar a associação entre uso de indicadores de desempenho associáveis às perspectivas do Balanced Scorecard (BSC) e fatores contingenciais em empresas de construção civil da cidade do Recife. A teoria da contingência enfatiza como os fatores contingenciais impactam o funcionamento e a estrutura das organizações e consequentemente o desempenho. Nessa perspectiva, foi analisado o uso dos indicadores de desempenho associáveis às perspectivas do BSC, sob a ótica da teoria da contingencia. Quanto aos procedimentos metodológicos, de modo a atender ao objetivo desta pesquisa foi utilizado como instrumento de coleta de dados o questionário, aplicado junto a gestores de 20 empresas do setor da construção civil, localizadas na cidade do Recife. Para análise dos dados foi utilizada a estatística descritiva e o teste não paramétrico coeficiente de correlação de Spearman, com o auxílio do software STATISTICA for windows. Ao final da análise dos resultados pôde-se concluir que existe relação entre as diversas características dos gestores, das empresas e dos fatores relacionados à mensuração de desem- 
penho e o uso dos indicadores das quatro perspectivas do BSC, ou seja, evidenciou-se que os fatores contingenciais influenciam a maneira de gerir as empresas conforme preconizado na teoria da contingência.

Palavras-chave: Mensuração de desempenho; Indicadores de desempenho; Fatores contingenciais; Teoria da contingência.

\section{Abstract}

The objective of this work was to analyze the association between the use of performance indicators associated with the Balanced Scorecard (BSC) perspectives and contingency factors in construction companies in the city of Recife. Contingency theory emphasizes how contingency factors impact the functioning and structure of organizations and consequently performance. In this perspective, the use of the performance indicators associated to the BSC perspectives was analyzed, from the point of view of the contingency theory. As for the methodological procedures, in order to meet the objective of this research, the questionnaire was used as a data collection instrument, applied to managers of 20 companies in the civil construction sector, located in the city of Recife. For data analysis, the descriptive statistics and the non-parametric Spearman correlation coefficient test were used as an aid to the STATISTICA for windows software. At the end of the analysis of the results it was possible to conclude that there is a relationship between the different characteristics of managers, companies and factors related to the performance measurement and the use of the indicators of the four perspectives of BSC, in other words, it was evidenced that the factors contingencies influence the way companies are managed as recommended in contingency theory.

Keywords: Performance Measurement. Performance Indicators. Contingency Factors. Contingency Theory.

\section{INTRODUÇÃo}

O ambiente no qual as empresas desenvolvem suas operações está cada vez mais competitivo e imprevisível em decorrência de diversos fatores que se sobrepõem e interferem na gestão das entidades afetando o seu desempenho. Neste contexto, dinâmica e complexidade representam características intrínsecas ao ambiente 
empresarial contemporâneo e são fatores responsáveis por ocasionar mudanças na maneira pela qual as organizações são geridas (ARAÚJO; CALLADO; CAVALCANTI, 2014).

Devido às rápidas mudanças ambientais, o desempenho das organizações tem sido submetido a vários desafios, fato este que pode ocasionar sérios problemas e até mesmo o eventual fracasso do negócio (SOROOSHIAN et al., 2016). Dessa maneira, as organizações necessitam medir o seu desempenho com a finalidade de se manterem competitivas frente às adversidades do ambiente. Nesse contexto, Waggoner, Neely e Kennerley (1999) afirmam que a medição de desempenho pode realizar um papel importante à medida que concentra as pessoas e os recursos em aspectos específicos do negócio.

Nesse sentido, Callado et al. (2008) entendem que a medição de desempenho deve ser tratada como uma operação estratégica pelo fato desta gerar informações centrais sobre a gestão, pois é através da mensuração de desempenho que a organização obtém relatórios e indicadores que demonstram como ela está em relação às metas estabelecidas, e desta forma controla e conhece seu desempenho econômico-financeiro e a eficiência operacional. Devido a essa necessidade de vigilância com o desempenho empresarial, Venkatraman e Ramanujam (1986) afirmam que o desempenho é um tema recorrente e de interesse tanto para acadêmicos quanto para gestores.

De acordo com Siqueira (2014), para avaliar o desempenho, as empresas se utilizam de sistemas de medição que possibilitam gerenciar os resultados de suas atividades por meio de indicadores. Para Nakamura e Mineta (2001), os gestores formulam indicadores que possibilitam monitorar a implementação da estratégia, bem como o que ocorre em seu ambiente de maneira a possibilitar reforços e alterações das estratégias competitivas. Nesse sentido, Maltempi (2014) afirma que para se tornar competitiva, a organização precisa elaborar estratégias, mas também precisa medir, comparar e tomar decisões por meio de indicadores. Ainda segundo essa autora, as estratégias precisam abranger novas perspectivas, financeiras e não financeiras, para melhorar o desempenho e tentar manter a empresa no mercado.

Nessa perspectiva, Quesado, Guzmán e Rodrigues (2014) as- 
severam que o ambiente globalizado tem exigido das organizações novas formas e estruturas de gestão ao ponto que nas últimas décadas foram desenvolvidos novos modelos e ferramentas de controle de gestão que combinam medidas de desempenho financeiras e não financeiras com o objetivo de melhorar a ligação entre a estratégia e a medição de desempenho. Dentre esses modelos desenvolvidos está o Balanced Scorecard (BSC) cujos indicadores frequentemente presentes em suas perspectivas são abordados neste estudo.

Beuren e Fiorentin (2014), afirmam que a postura estratégica de uma organização está associada a fatores contingentes como ameaças internas e externas e estas, por sua vez são afetadas pelas restrições políticas, econômicas e culturais. A Teoria da Contingência explica como os fatores externos influenciam no crescimento e sobrevivência das organizações, conforme o ambiente no qual estejam inseridas.

No escopo desta pesquisa encontra-se a indústria da construção civil, a qual segundo dados da Pesquisa Anual da Indústria da Construção (PAIC), (IBGE, 2015), no ano de 2015, as empresas de construção realizaram incorporações, obras e/ou serviços no valor corrente de $\mathrm{R} \$ 354,4$ bilhões, registrando, em termos reais, retração de $16,5 \%$ na comparação com o ano anterior. Houve também retração no número de pessoas empregadas, passando de 2,9 milhões em 2014 para 2,4 milhões em 2015. Segundo dados divulgados pelo Ministério do Trabalho e Emprego (MTE), constantes da Relação Anual de Informações Sociais (RAIS), no ano de 2016 o Brasil contabilizou 2.122.335 trabalhadores na indústria da construção civil. No Estado de Pernambuco esse contingente representou 74.022 trabalhadores e na cidade do Recife este número alcançou 42.631 trabalhadores (MTE, 2016).

Assim, diante do atual cenário da indústria da construção civil, no qual as empresas estão sujeitas a modificações contínuas em suas atividades e estratégias, e onde se apresentam diversos fatores contingentes como variação das taxas de juros, oscilação do crédito, mudanças no mercado de trabalho, alterações na legislação dentre outros, surge a seguinte pergunta de pesquisa: Qual a relação entre uso de indicadores de desempenho organizacional e fatores contingenciais?

Dessa forma, o objetivo deste artigo é analisar a associação entre 
uso de indicadores de desempenho associáveis às perspectivas do Balanced Scorecard (BSC) e fatores contingenciais em empresas de construção civil da cidade do Recife.

Além desta seção, o presente artigo é constituído pelo referencial conceitual na seção 2 , procedimentos metodológicos na seção 3, análise e discussão dos resultados na seção 4, conclusão na seção 5 e pelas referências utilizadas.

\section{REFERENCIAL CONCEITUAL}

\subsection{Indicadores de Desempenho}

Segundo Moreira (2002, p. 15), “o indicador é o resultado de uma medida ou de mais medidas que tornam possível a compreensão da evolução do que se pretende avaliar a partir dos limites (referências ou metas) estabelecidos". Francischini e Francischini (2017) entendem indicadores como sendo medidas qualitativas ou quantitativas que mostram o estado de uma operação, processo ou sistema.

Ferreira, Cassiolato e Gonzalez (2009, p. 24) assim definem um indicador:

O indicador é uma medida, de ordem quantitativa ou qualitativa, dotada de significado particular e utilizada para organizar e captar as informações relevantes dos elementos que compõem o objeto da observação. É um recurso metodológico que informa empiricamente sobre a evolução do aspecto observado.

De acordo com Callado, Chaves e Callado (2014) e Santos, Quel, Vieira e Rosini (2019), o uso de indicadores de desempenho consiste na estimação de quocientes ou índices, os quais consideram os dados contábeis como fontes de informações que possibilitam identificar a evolução dos aspectos financeiros das empresas além de permitir comparações e projeções.

Melnyk, Stewart e Swink (2004), afirmam que métricas e medição de desempenho são os elementos críticos na tradução da realidade ou da missão da organização, ou seja, métricas e estratégias possuem direta associação entre si, ou seja, uma métrica ou indicador é uma medida verificável, indicada em termos quantitativos ou 
qualitativos e definida em relação a um ponto de referência. Desse modo, Wernke e Junges (2017, p.59) asseveram que "um indicador não é apenas uma estatística, pois representa uma variável que assume um valor em um tempo específico".

Os indicadores de desempenho possuem distintas classificações, tais como: financeiros e não financeiros; internos e externos; de tendência e de ocorrência; quantitativos e qualitativos. Dentre essas classificações, a mais comumente utilizada é a que diferencia os indicadores de desempenho entre financeiros e não financeiros (MARQUEZAN; DIEHL; ALBERTON, 2013). Destarte, Barros, Libonati e Barbosa (2012, p. 931) afirmam que essa classificação dos indicadores em dois grandes grupos, financeiros e não financeiros ocorre "devido ao novo contexto em que as empresas estão inseridas, onde os aspectos intangíveis se sobrepõem aos aspectos tangíveis das organizações".

Indicadores financeiros "são os indicadores mais tradicionalmente utilizados pelas empresas para a avaliação de seu desempenho", esses indicadores "objetivam orientar a organização para a tomada de decisão com relação a questões econômicas e patrimoniais" (MARQUEZAN; DIEHL; ALBERTON, 2013, p. 48). Os indicadores financeiros expressam em unidades monetárias os aspectos mensuráveis da organização e estão relacionados com as "abordagens que utilizam medidas puramente financeiras tais como lucratividade, custo de mão de obra, retorno sobre investimento, lote econômico e fluxo de caixa" (TEZZA; BORNIA; VEY, 2010, p. 78).

De acordo com Kennerley e Neely (2002), no início dos anos 1980 havia uma crescente percepção de que não era mais apropriado avaliar o desempenho das organizações usando como único critério as medidas financeiras devido à crescente complexidade das instituições e dos mercados nos quais competiam.

O reconhecimento das limitações dos indicadores financeiros em mensurar de maneira adequada o desempenho das organizações impulsionou a utilização de indicadores não financeiros como forma de tornar o processo de mensuração mais eficiente visto que "os indicadores não financeiros podem ser considerados estratégicos para a gestão dos negócios e para a formação de vantagens competitivas" (WERNKE; JUNGES, 2017, p. 57).

Os indicadores não financeiros apresentam a capacidade de 
transmitir informações com maior facilidade e podem ser expressos em unidades de medida de mais fácil interpretação, tais como quantidades, metros, volumes e horas. Estes indicadores servem como molas propulsoras para motivar o desempenho dos processos em toda a organização, além de possibilitarem correções durante o curso das operações em virtude de transmitirem informações de tendências (MARQUEZAN; DIEHL; ALBERTON, 2013).

\subsection{Teoria da Contingência}

Conforme Beuren e Fiorentin (2014), ambientes externos cada vez mais incertos têm feito com que os gestores necessitem de informações úteis e tempestivas para melhorar o desempenho organizacional e obter vantagem competitiva. Com efeito, a Teoria da Contingência explica como os fatores externos influenciam no crescimento e sobrevivência das organizações, conforme o ambiente no qual estejam inseridas. Chenhall (2007, p. 191), assevera que "o termo contingência significa que algo é verdadeiro somente em condições especificadas." Para esse autor, a pesquisa baseada em contingências tem seus fundamentos na Teoria Organizacional, que considera apenas variáveis contextuais organizacionais e ambientais.

A abordagem contingencial é uma vertente das teorias organizacionais, segundo a qual a organização é vista como um sistema aberto. Enquanto sistema aberto, a organização interage com o ambiente e com outros fatores contingenciais como tecnologia, estrutura, estratégia, porte, dentre outros (KLEIN; ALMEIDA, 2017). Segundo Donaldson (2015, p. 609), a teoria da contingência estrutural, "é uma teoria sobre como uma estrutura organizacional precisa se ajustar a fatores, a exemplo de sua estratégia e tamanho, a fim de produzir alto desempenho".

Conforme Marques e Souza (2010), os objetivos principais da Teoria da Contingência são estudar e conhecer os fatores internos e externos à organização e medir o nível de adequação estrutural das organizações. Os fatores contingenciais, estudados na Teoria da Contingência, são fatores caracterizados por variáveis que podem influenciar o processo decisório e afetar a estrutura organizacional (MARQUES; SOUZA, 2010; SANTOS et al., 2016). Nessa perspectiva, Silva e Callado (2018), afirmam que a análise dos fatores contingen- 
ciais tem demonstrado que não existe uma estrutura organizacional única e universal a ser aplicada em todas as organizações.

Otley (2016) afirma que as pesquisas das últimas décadas apresentaram uma lista extensa de contingências possivelmente significativas que são enfrentadas pelas organizações. Essas contingências são estudadas na forma de variáveis, as quais se classificam em dependentes e independentes, sendo as variáveis dependentes divididas em internas e externas. As variáveis dependentes mais examinadas são desempenho, comportamento orçamentário, eficácia, design do sistema de controle de gestão e seu uso, medidas de desempenho, satisfação no trabalho, mudanças nas práticas e inovação de produtos.

Com relação às variáveis independentes externas, as mais examinadas são: tecnologia, concorrência no mercado ou hostilidade, incerteza ambiental, cultura nacional. Já as variáveis independentes internas mais examinadas são: tamanho ou porte organizacional, estrutura, estratégia, sistemas de compensação, sistemas de informação, variáveis psicológicas, participação dos funcionários nos sistemas de controle, posição no mercado, estágio do ciclo de vida do produto e mudança de sistemas (OTLEY, 2016).

\section{Procedimentos metodológicos}

\subsection{Tipologia da pesquisa}

As pesquisas científicas recebem diversas classificações conforme as características apresentadas. Nesse sentido Gil (2008), classifica as pesquisas com base em seus objetivos gerais em três grandes grupos, a saber: pesquisas exploratórias, pesquisas descritivas e pesquisas explicativas. A pesquisa descritiva tem como objetivo primordial a descrição das características de determinada população ou fenômeno ou, então, o estabelecimento de relações entre variáveis. A pesquisa exploratória tem como objetivo proporcionar maior familiaridade com o problema, com vistas a torná-lo mais explícito ou a constituir hipóteses.

Com relação aos objetivos, esta pesquisa pode ser classificada como exploratória e descritiva acerca do tema mensuração de desempenho, visto que a pesquisa descritiva observa, registra, 
analisa e correlaciona fatos ou fenômenos (variáveis) sem manipulá-los (CERVO; BERVIAN; SILVA, 2007). No tocante à abordagem do problema de pesquisa, esta é uma investigação predominantemente quantitativa, visto que nas pesquisas quantitativas tudo pode ser quantificável, o que significa traduzir em números, opiniões e informações para classificá-las e analisá-las, fazendo uso de técnicas estatísticas (PRODANOV; FREITAS, 2013).

Como procedimento metodológico, optou-se por uma survey ou pesquisa de levantamento, o qual segundo Prodanov e Freitas (2013), envolve a interrogação direta das pessoas cujo comportamento se quer conhecer, utilizando-se de questionários. Ainda conforme esses autores, a partir da survey, solicitam-se informações a um grupo significativo de participantes e em seguida, mediante análise quantitativa, obtêm-se as conclusões acerca dos dados coletados. O instrumento do qual se fez uso para a coleta dos dados analisados nesta pesquisa foi um questionário com perguntas fechadas. Para tanto foi utilizada uma adaptação do questionário contido no protocolo de pesquisa desenvolvido e aplicado por Silva e Callado (2018a), o qual tratou de investigar fatores contingenciais e indicadores de desempenho na indústria da construção civil de João Pessoa/PB.

Para dimensionar o conjunto de empresas a serem pesquisadas, ou seja, para se chegar ao universo dessa pesquisa, inicialmente foi realizada consulta no sítio institucional do Sindicado da Indústria da Construção Civil no Estado de Pernambuco (SINDUSCON-PE) com a finalidade de verificar a relação das empresas associadas àquele sindicato, no ano de 2018. A partir dessa consulta, verificou-se que a listagem de empresas associadas era composta por 162 organizações, das quais 123 estavam sediadas na cidade de Recife, e dentre estas, apenas 94 empresas exerciam atividade econômica principal compatível com os objetivos da pesquisa e compõem o seu universo.

Devido a baixa receptividade das empresas consultadas em aceitar participar do estudo, recorreu-se a um modelo não probabilístico de amostragem. Dessa forma, a amostra de pesquisa é não probabilística, escolhida por acessibilidade ou conveniência, constituída por 20 empresas que aceitaram responder o questionário de pesquisa. O contato com os gestores investigados se deu através de contatos por telefone, envio de e-mails e contato presencial. A coleta de dados 
teve início em outubro de 2018 e durou até fevereiro de 2019.

\subsection{Variáveis investigadas}

Para operacionalização desta pesquisa foram utilizados quatro grupos de variáveis. O primeiro grupo foi composto por fatores internos relacionados às características dos gestores das organizações pesquisadas, assim composto: (V1) Faixa Etária do Entrevistado; (V2) Nível de Escolaridade; e (V3) Experiência Profissional.

No segundo grupo foram agrupados os fatores contingentes relativos às características das empresas participantes da pesquisa, sendo composto por fatores internos e externos como: (V4) Tempo de atuação da empresa no mercado; (V5) Número de empregados; (V6) Grau de formalização dos processos operacionais; (V7) Prioridade estratégica; (V8) Estrutura hierárquica.

O conjunto de variáveis consideradas no terceiro grupo trata dos aspectos relacionados aos critérios de mensuração de desempenho adotados pelas empresas, sendo formado pelos fatores internos: (V9) Critério adotado para a seleção dos indicadores de desempenho; (V10) Procedimentos referentes à mensuração do desempenho no âmbito da empresa; e (V11) Frequência dos relatórios sobre desempenho.

No tocante ao quinto grupo, foram elencadas variáveis para investigar o uso (ou não uso) de indicadores de desempenho associáveis às perspectivas do Balanced Scorecard. Foram considerados 36 indicadores, assim distribuídos dentre as dimensões do BSC:

Perspectiva financeira: (1) lucratividade; (2) rentabilidade; (3) faturamento; (4) crescimento das vendas; (5) custos totais; (6) custos unitários; (7) fluxo de caixa; (8) retorno do investimento; (9) inventários; (10) preço dos produtos; e (11) capital de giro.

Perspectiva dos clientes: (12) quantidade de clientes; (13) novos clientes; (14) satisfação de clientes; (15) qualidade dos produtos; (16) devolução de produtos; (17) tempo de entrega; (18) pontualidade de entrega; (19) responsividade; e (20) crescimento da participação de mercado.

Perspectiva dos processos internos: (21) tempo de realização das operações; (22) flexibilidade de entrega; (23) tempo de estocagem; (24) fornecedores; (25) flexibilidade de volume operacional; (26) uso da capacidade instalada; (27) pós-venda; (28) entregas no prazo; e 
(29) desperdícios.

Perspectiva da aprendizagem e crescimento: (30) produtividade dos empregados; (31) satisfação dos empregados; (32) rotatividade de empregados; (33) flexibilidade dos empregados; (34) inovação nos produtos; (35) investimentos em treinamento; e (36) gestão de risco.

\subsection{Técnicas de análise estatística}

Para atingir o objetivo proposto nesta pesquisa, a análise dos dados coligidos foi realizada em duas etapas e foram utilizados dois métodos estatísticos distintos, a análise descritiva ou unidimensional e o teste não paramétrico coeficiente de correlação de Spearman. O primeiro método consistiu na análise descritiva das variáveis relacionadas à caracterização dos gestores, das empresas e dos aspectos relacionados aos critérios de mensuração de desempenho.

O segundo método consistiu em aplicar o coeficiente de correlação de Spearman para analisar as relações entre o uso de indicadores de desempenho organizacional e os fatores contingenciais investigados. Os procedimentos foram realizados com a utilização do software STATISTICA for Windows. Na aplicação do coeficiente de correlação de Spearman ( $\mathrm{r}$ ) foi considerado o nível de significância de 95\% $(\alpha=0,05)$ como referência mínima aceitável para determinar a significância estatística. Os critérios utilizados para interpretar a magnitude da corelação foram os de Franzblau (1958). De acordo com Franzblau (1958) apud Pereira et al. (2016): Se $r=0$, não existe relação linear entre as variáveis; Se $|\mathrm{r}|<0,20$ a correlação é negligenciável; Se 0,20 < | r $\mid<0,40$, a correlação é fraca; Se 0,40<| r | $<0,60$ a correlação é moderada; Se $0,60<\mid$ r $\mid<0,80$, a correlação é forte; e Se | r |>0,80, a correlação é muito forte.

\section{ANÁliSE E DISCUSSÃo DOS RESUlTADOS}

\subsection{Caracterização dos gestores}

Aqui foram abordadas questões relacionadas às características do perfil dos gestores das empresas pesquisadas. Foram investigadas as seguintes variáveis: (V1) Faixa Etária do Entrevistado; (V2) Nível de Escolaridade; e (V3) Experiência Profissional.

Com relação à variável Faixa Etária do Entrevistado, os resul- 
tados mostraram que a maioria dos respondentes tem idade entre 31 e 50 anos. A parcela dos respondentes com essa faixa etária corresponde a $85 \%$ dos pesquisados, sendo $50 \%$ com idade entre 31 e 40 anos e 35\% com idade entre 41 e 50 anos. A participação de respondentes com idade menor que 30 anos equivale a $10 \%$ dos pesquisados enquanto os respondentes com idade maior que 50 anos corresponde a $5 \%$ dos gestores entrevistados.

Os resultados encontrados aqui divergem um pouco dos resultados encontrados por Silva, Callado e Callado (2016) e Holanda (2007) que analisaram esse mesmo setor na cidade de João Pessoa/ PB. Silva, Callado e Callado (2016) encontraram 58,62\% de gestores na faixa etária entre 31 e 50 anos. Na faixa etária menor que 30 anos, os autores encontraram $17,24 \%$ dos respondentes e $24,14 \%$ na faixa etária maior que 50 anos. Holanda (2007) também encontrou como faixas etárias preponderantes entre os gestores, as localizadas entre 31 e 50 anos com $67,8 \%$ de respostas, sendo $32,10 \%$ na faixa de idade entre 31 e 40 anos e 35,70 na faixa entre 41 e 50 anos. Nas faixas etárias menores que 30 anos e maior que 50 anos foram encontradas, respectivamente, $14,30 \%$ e $17,90 \%$ de respostas.

No tocante à variável Nível de Escolaridade, os resultados evidenciaram que dentre os pesquisados, 100\% possui formação escolar de nível superior, sendo 30\% de graduados e $70 \%$ de pós-graduados. A pesquisa não procurou identificar, entre os pós-graduados, qual o nível da pós-graduação, se especialização, mestrado ou doutorado. Os resultados também demonstraram que nenhum dos respondentes informou possuir apenas o ensino médio.

Fazendo o cotejamento dos resultados aqui encontrados com as pesquisas realizadas por Silva, Callado e Callado (2016) e Holanda (2007) é possível encontrar algumas divergências. Silva, Callado e Callado (2016) encontraram 10,34\% de respostas para o nível de escolaridade ensino médio, 58,62\% para ensino superior/graduação e 31,04\% para pós-graduação. Já Holanda (2007) encontrou os seguintes resultados $75 \%$ para o ensino superior/graduação, 25\% para pós-graduação e $0 \%$ para ensino médio.

De acordo com as informações obtidas acerca da variável Experiência Profissional, verificou-se que $75 \%$ dos respondentes informaram possuir mais de 10 anos de experiência profissional, sendo 
$60 \%$ enquadrados na faixa entre 11 e 20 anos de experiência e $15 \%$ com experiência superior a 20 anos de mercado. Outros $25 \%$ de respondentes informaram estar na faixa de experiência com tempo de atuação menor que 10 anos de mercado.

Comparando os resultados aqui encontrados com os resultados coligidos na pesquisa de Silva, Callado e Callado (2016) observou-se que na pesquisa desses autores houve uma distribuição mais uniforme das frequências de ocorrências de respostas dentre as três faixas pesquisadas, sendo $31,04 \%$ para experiência menor que 10 anos, $34,48 \%$ entre 11 e 20 anos de experiência e 34,48\% para experiência maior que 20 anos. No trabalho de Holanda (2007), a autora encontrou $46,40 \%$ para menos de 10 anos de experiência, 39,30\% entre 11 e 20 anos e 14,30\% para tempo maior que 20 anos de experiência.

Esses resultados encontrados para as características dos gestores das empresas pesquisadas indicam que a grande maioria é formada por profissionais experientes, com mais de 10 anos de vivência no mercado, com maturidade, ótimo nível de formação acadêmica e bons conhecimentos sobre as organizações nas quais atuam.

\subsection{Caracterização das empresas pesquisadas}

Nesse tópico foram abordados fatores relacionados com as características estruturais das empresas de construção civil participantes da pesquisa. Nessa perspectiva foram investigadas as seguintes variáveis: (V4) tempo de atuação da empresa no mercado; (V5) número de empregados; (V6) grau de formalização dos processos operacionais; (V7) prioridade estratégica; e (V8) estrutura hierárquica.

No tocante ao tempo de atuação da empresa no mercado, verificou-se que $55 \%$ das empresas constituintes da amostra da pesquisa apresentou atuação no mercado superior aos 20 anos. Observou-se que $45 \%$ das empresas pesquisadas atuam no mercado da construção civil entre 10 e 20 anos. Da amostra de empresas pesquisadas, nenhuma indicou ter tempo de atuação no mercado inferior a 10 anos. Os resultados sugerem certo amadurecimento das empresas da amostra de pesquisa, atuantes no setor da construção civil da cidade do Recife em virtude de $100 \%$ das empresas pesquisadas estarem no mercado há mais de 10 anos.)

(Holanda (2007) encontrou 42,86\%, 39,29\% e 17,85\% para as 
respectivas faixas de tempo de atuação profissional, menor que 10 anos, entre 10 e 20 anos e maior que 20 anos, respectivamente. Silva, Callado e Callado (2016) encontraram 20,69\%, 51,72\% e $27,59 \%$ para aquele mesmo setor da economia e região, 10 anos após a pesquisa de Holanda.

O número de empregados foi utilizado como parâmetro para classificação do porte das empresas, conforme consideração adotada pelo SEBRAE (2013). Os resultados demonstraram que $20 \%$ da amostra de pesquisa é constituída por empresas enquadradas como microempresa, com até 19 empregados. Outros 35\% das empresas constituintes da amostra é formada por empresas de pequeno porte (entre 19 e 99 empregados). Além disso, 30\% das empresas pesquisadas enquadram-se como sendo de médio porte (entre 99 até 499 empregados) e 15\% são classificadas como empresa de grande porte (acima de 499 empregados).

Pesquisando a aderência de indicadores de desempenho associados às perspectivas do BSC por empresas do setor da construção civil de João Pessoa/PB, Silva e Callado (2018b) encontraram as seguintes respostas: $24,14 \%$ para micro empresas; $48,28 \%$ empresas de pequeno porte; $20,69 \%$ empresas de médio porte e 6,89\% empresas de grande porte. A comparação dos resultados das duas pesquisas sugere que o setor aqui pesquisado tenha se estruturado em período anterior ao setor estudado na pesquisa de Silva e Callado (2018b) e por esse motivo existe uma concentração maior de empresas médias e grandes.

Quanto à estrutura hierárquica das empresas pesquisadas foi observado que $15 \%$ apresentam dois níveis hierárquicos. Um quantitativo de $75 \%$ das empresas possuem três níveis hierárquicos e outras $10 \%$ informaram manter quatro níveis. Como é possível observar, $85 \%$ das empresas pesquisadas apresentam três ou mais níveis hierárquicos organizacionais, o que sugere que existe certa descentralização das decisões estratégicas nas empresas da amostra de pesquisa. Silva, Callado e Callado (2016), encontraram 58,62\% para empresas com dois níveis hierárquicos, 27,59\% de empresas com três níveis e 13,79\% de empresas com quatro níveis hierárquicos. Os resultados sugeriram certa centralização das decisões estratégicas nas empresas componentes daquele setor estudado.

Em relação ao grau de formalização dos processos operacio- 
nais foi possível visualizar que em $20 \%$ das empresas os processos são planejados, supervisionados e revisados, também em $20 \%$ das empresas os processos são continuamente aprimorados. Para 10\% das empresas consultadas, os processos possuem metas específicas definidas pela empresa e para $30 \%$ das respondentes os processos são padronizados e aprimorados. Para $20 \%$ das empresas estudadas os processos não são padronizados. Os resultados evidenciaram que $80 \%$ das empresas mantêm processos com algum grau de padronização, planejamento e aprimoramento, o que sugere que essas empresas se utilizam de estratégias planejadas para se protegerem de eventuais mudanças em seu ambiente.

Quanto à prioridade estratégica adotada pela empresa possível visualizar que em $45 \%$ das empresas respondentes a prioridade estratégica é conquistar mercado a partir da oferta de produtos/ serviços mais baratos que a concorrência, ou seja, essas empresas adotam a postura estratégica de liderança em custos. Nos outros 55\% de empresas respondentes a prioridade estratégica é o desenvolvimento de produtos/serviços de qualidade superior ou com algum atributo que justifique preços mais altos que a concorrência, ou seja, as empresas adotam a estratégia de diferenciação de produto.

Os resultados aqui encontrados sugerem que entre as empresas da amostra pesquisada existe certo equilíbrio na escolha da prioridade estratégica, porém observa-se uma pequena vantagem da estratégia de diferenciação sobre a liderança de custo. Este fato corrobora o resultado do estudo de Abdel-Kader e Luther (2008), no qual os autores afirmam que as organizações de sucesso estão migrando para estratégias competitivas baseadas na diferenciação, com maior ênfase em estruturas baseadas em equipes e em práticas de contabilidade gerencial avançadas, utilizando-se uma série de medidas de desempenho não financeiras.

\subsection{Caracterização da mensuração de desempenho}

Nesse tópico foram abordadas questões relacionadas com o processo de mensuração de desempenho adotado pelas empresas pesquisadas. Esse item foi constituído pelos fatores internos: (V9) Critério adotado para a seleção dos indicadores de desempenho; (V10) Procedimentos referentes à mensuração do desempenho; e 
(V11) Frequência dos relatórios sobre desempenho.

Com relação ao critério adotado para a seleção dos indicadores de desempenho, os resultados mostraram que 10\% das empresas pesquisadas utilizam como critério para selecionar seus indicadores, o fato destes serem muito usados pelas empresas do setor. Outros $40 \%$ das empresas pesquisadas informaram que utilizam como critério para seleção dos indicadores a indicação de especialistas e consultores, e em $50 \%$ das empresas pesquisadas o critério adotado é o fato dos indicadores estarem atrelados a metas estratégicas da empresa. Os resultados obtidos convergem no sentido do que preconiza a literatura sobre o tema, quando nesta se encontra que os indicadores possibilitam monitorar a implementação da estratégia, ou seja, os indicadores podem ser estratégicos para a gestão dos negócios (KAPLAN; NORTON, 1997; NAKAMURA; MINETA, 2001; WERNKE; JUNGES, 2017).

No tocante aos procedimentos referentes à mensuração do desempenho foi possível observar que entre as empresas pesquisadas, $25 \%$ delas informaram que nos procedimentos de mensuração de desempenho da empresa não há padronização nem regularidade. Além disso, $20 \%$ das empresas respondentes informaram que há padronização, mas não há regularidade e 55\% disseram que há padronização e regularidade nos procedimentos de mensuração de desempenho. Esses resultados sugerem que os gestores das empresas da amostra de pesquisa estão preocupados com a regularidade dos procedimentos de mensuração de desempenho, pois conforme assevera Relvas (2008), a mensuração de desempenho é um tema de grande relevância por que a qualidade das decisões organizacionais depende da qualidade da mensuração.

No que concerne à frequência dos relatórios sobre desempenho foi possível observar que $60 \%$ das empresas disseram que a frequência dos relatórios é mensal. Outros 35\% afirmaram ser semestral a periodicidade dos relatórios sobre desempenho no âmbito da empresa e apenas $5 \%$ das empresas participantes da pesquisa informaram ser semanal a frequência dos relatórios. Em relação à mensuração de desempenho, Ribeiro, Macedo e Marques (2012) afirmam que este deve ser um processo permanente e repetitivo. Wernke e Junges (2017) afirmam que esse processo deve ser executado periodicamente, pois permite que a empresa conheça e 
compare os desempenhos do passado e do presente, com vistas a estabelecer uma tendência de desempenho futuro. Nesse contexto, entende-se que os resultados aqui encontrados, que indicam que 35\% das empresas adotam periodicidade semestral para seus relatórios de desempenho não seja uma boa estratégia.

\subsection{Relações entre uso de indicadores de desempenho e ca- racterísticas dos gestores}

As informações coletadas junto às empresas integrantes da amostra da pesquisa foram compiladas em uma base de dados com vistas a viabilizar a execução do teste estatístico não paramétrico coeficiente de correlação de Spearman. Inicialmente foram consideradas as relações entre o uso de indicadores de desempenho da perspectiva financeira e as características dos gestores. Os resultados estão apresentados na Tabela 1.

Tabela 1 - Relações entre uso de indicadores de desempenho da perspectiva financeira e características dos gestores

\begin{tabular}{l|l|l|l}
\hline \multirow{2}{*}{ Indicadores } & \multicolumn{3}{|l}{ Correlação } \\
\cline { 2 - 4 } & Faixa Etária (V1) & Escolaridade (V2) & $\begin{array}{l}\text { Experiência Pro- } \\
\text { fissional (V3) }\end{array}$ \\
\hline Lucratividade & 0,414102 & $-0,350438$ & 0,386164 \\
\hline Rentabilidade & $\mathbf{0 , 3 1 9 2 6 9}$ & $-0,030557$ & $\mathbf{0 , 2 9 1 1 6 2}$ \\
\hline Faturamento & 0,414102 & $-0,350438$ & 0,386164 \\
\hline Crescimento das vendas & 0,193921 & $-0,133631$ & 0,141479 \\
\hline Custos totais & $-0,130769$ & 0,150188 & $-0,340733$ \\
\hline Custos unitários & $\mathbf{- 0 , 2 3 9 4 5 1}$ & $\mathbf{0 , 2 7 5 0 1 0}$ & 0,083189 \\
\hline Fluxo de caixa & 0,319269 & $-0,336123$ & 0,291162 \\
\hline Retorno do investimento & 0,049794 & 0,022875 & $-0,051898$ \\
\hline Inventários & 0,203617 & 0,133631 & 0,010106 \\
\hline Preço dos produtos & $\mathbf{0 , 3 1 8 1 2 5}$ & 0,125988 & $\mathbf{0 , 4 5 7 3 3 0}$ \\
\hline Capital de Giro & $-0,009696$ & $-0,133631$ & $-0,030317$ \\
\hline
\end{tabular}

Fonte: Dados da pesquisa, 2019.

Analisando os resultados constantes na Tabela 1 é possível 
observar que a variável V1 (faixa etária) se correlaciona com os indicadores lucratividade e faturamento de forma positiva e com magnitude moderada. Essa variável também apresentou correlação de forma positiva e com magnitude fraca com os indicadores rentabilidade, fluxo de caixa e preço dos produtos, relacionando-se ainda com o indicador custos unitários de forma negativa e com fraca magnitude. Esse resultado indica que a faixa etária dos gestores da amostra de empresas pesquisadas influencia o uso de indicadores de desempenho que estão diretamente relacionados ao resultado financeiro.

A variável V2 (nível de escolaridade) apresentou correlação positiva e de magnitude fraca com o indicador custos unitários. V2 também se correlaciona de forma negativa e com magnitude fraca, com os indicadores lucratividade, faturamento e fluxo de caixa. De acordo com os resultados encontrados, o aumento do nível de escolaridade dos gestores da amostra pesquisada diminui o uso de indicadores relacionados ao resultado financeiro como lucratividade, faturamento e fluxo de caixa.

A variável V3 (experiência profissional) apresentou correlação positiva e fraca com os indicadores lucratividade, rentabilidade, faturamento e fluxo de caixa, e com preço dos produtos a correlação é positiva e moderada. Esse resultado sugere que quanto maior a experiência profissional dos gestores das empresas pesquisadas maior é a tendência de preocupação com os fatores que influenciam o resultado da empresa.

Pesquisa realizada por Silva, Callado e Callado (2016) revelou resultados distintos dos aqui encontrados. No trabalho dos supracitados autores, nenhuma das características dos gestores se mostrou correlacionada, em nível estatisticamente significativo, ao uso de indicadores da perspectiva financeira indicando independência da utilização desses indicadores a partir dos aspectos pessoais dos gestores.

Na sequência foram analisadas as possíveis correlações entre o uso de indicadores de desempenho da perspectiva clientes e as características dos gestores das empresas pesquisadas cujos resultados estão dispostos na Tabela 2.

Tabela 2 - Relações entre uso de indicadores de desempenho da perspec- 
tiva clientes e características dos gestores

\begin{tabular}{l|l|l|l}
\hline \multirow{2}{*}{ Indicadores } & \multicolumn{2}{l}{ Correlação } & \multicolumn{2}{l}{} \\
\cline { 2 - 4 } & $\begin{array}{l}\text { Faixa Etária } \\
(\mathrm{V} 1)\end{array}$ & $\begin{array}{l}\text { Escolarida- } \\
\text { de (V2) }\end{array}$ & $\begin{array}{l}\text { Experiência } \\
\text { Profissional } \\
\text { (V3) }\end{array}$ \\
\hline Quantidade de clientes & $\mathbf{0 , 2 5 7 7 9 6}$ & $-0,065795$ & $\mathbf{0 , 4 7 7 6 6 5}$ \\
\hline Novos clientes & $-0,077568$ & $-0,089087$ & $-0,121268$ \\
\hline Satisfação de clientes & $-0,020731$ & $\mathbf{- 0 , 2 8 5 7 1 4}$ & $-0,054017$ \\
\hline Qualidade dos produtos & $-0,142608$ & $-0,125988$ & $-0,080033$ \\
\hline Devolução de produtos & 0,095480 & $-0,065795$ & $\mathbf{0 , 3 0 8 4 9 2}$ \\
\hline Tempo de entrega & $\mathbf{0 , 4 1 4 6 2 0}$ & 0,190476 & $\mathbf{0 , 2 9 1 6 9 2}$ \\
\hline Pontualidade de entrega & 0,118752 & $\mathbf{0 , 3 2 7 3 2 7}$ & 0,099015 \\
\hline Responsividade & 0,152002 & $\mathbf{0 , 2 1 8 2 1 8}$ & $-0,009901$ \\
\hline Crescimento da partici- & $-0,169301$ & $\mathbf{0 , 4 3 4 6 3 4}$ & $\mathbf{- 0 , 2 8 0 2 4 8}$ \\
pação de mercado & & & \\
\hline
\end{tabular}

Fonte: Dados da pesquisa, 2019.

Analisando os resultados contidos na Tabela 2 é possível observar que a variável V1 (faixa etária) se corelaciona de forma direta com os indicadores quantidade de clientes e tempo de entrega. Com o indicador tempo de entrega, a relação de V1 é moderada e com quantidade de clientes é fraca. Esses resultados indicam que quanto maior a faixa etária dos gestores da amostra de empresas pesquisadas, maior é o uso de indicadores relacionados com a fidelização de clientes como a quantidade de clientes e o tempo de entrega. A pesquisa de Silva, Callado e Callado (2016) também evidenciou que a faixa etária dos gestores exerce influência na utilização de indicadores de desempenho associados à perspectiva clientes do BSC.

O teste revelou que a variável V2 (escolaridade) se correlaciona de forma direta e moderada com o indicador crescimento da participação de mercado, e de forma direta e fraca com os indicadores pontualidade de entrega e responsividade. V2 também se relaciona de forma indireta e fraca com o indicador satisfação de clientes. Esses resultados sugerem que um maior nível de escolaridade dos gestores da amostra de empresas pesquisadas influencia diretamente, aumentando o uso de indicadores relacionados à pontualidade de entrega, responsividade e crescimento da participação de mercado. 
Por outro lado, o aumento da escolaridade dos gestores reduz o uso do indicador satisfação de clientes. Montenegro e Callado (2019) pesquisando fatores contingenciais e uso de indicadores no setor de confecção do vestuário de João Pessoa/PB identificaram que a escolaridade influência o uso de indicadores de desempenho da perspectiva clientes do BSC.

O teste também mostrou que existe relação direta entre a variável V3 (experiência profissional) e o uso dos indicadores quantidade de clientes, devolução de produtos e tempo de entrega. V3 também se correlaciona de forma indireta e fraca com o indicador crescimento da participação de mercado. Esses resultados sugerem que quanto maior a experiência profissional dos gestores da amostra pesquisada, maior o uso dos indicadores relacionados à devolução dos produtos e tempo de entrega, ao passo que o aumento na experiência profissional reduz o uso do indicador crescimento da participação de mercado.

Em seguida foram investigadas possíveis relações entre o uso de indicadores de desempenho da perspectiva processos internos e características dos gestores das empresas estudadas cujos resultados estão apresentados na Tabela 3.

Tabela 3 - Relações entre uso de indicadores de desempenho da perspectiva processos internos e características dos gestores

\begin{tabular}{l|l|l|l}
\hline \multirow{2}{*}{ Indicadores } & \multicolumn{2}{l|}{ Correlação } & \multicolumn{2}{l}{} \\
\cline { 2 - 4 } & Faixa Etária (V1) & $\begin{array}{l}\text { Escolaridade } \\
\text { (V2) }\end{array}$ & $\begin{array}{l}\text { Experiência } \\
\text { Profissional } \\
\text { (V3) }\end{array}$ \\
\hline Tempo de realização das operações & $\mathbf{0 , 2 5 7 7 9 6}$ & 0,153522 & 0,159222 \\
\hline Flexibilidade de entrega & $-0,043879$ & 0,125988 & $\mathbf{- 0 , 2 8 5 8 3 1}$ \\
\hline Tempo de estocagem & 0,225628 & $\mathbf{0 , 2 1 8 2 1 8}$ & $\mathbf{- 0 , 0 7 4 2 6 1}$ \\
\hline Fornecedores & $-0,142608$ & 0,125988 & $\mathbf{- 0 , 2 7 4 3 9 8}$ \\
\hline Flexibilidade de volume operacional & 0,083126 & $\mathbf{0 , 2 1 8 2 1 8}$ & $\mathbf{- 0 , 2 8 4 6 6 7}$ \\
\hline Uso da capacidade instalada & 0,145117 & 0,047619 & $\mathbf{- 0 , 1 0 8 0 3 4}$ \\
\hline Pós-venda & 0,155483 & $-0,047619$ & $\mathbf{0 , 2 9 1 6 9 2}$ \\
\hline Entregas no prazo & 0,545417 & $-0,030557$ & $\mathbf{0 , 2 9 1 1 6 2}$ \\
\hline Desperdícios & $\mathbf{- 0 , 3 7 3 1 5 8}$ & $-0,047619$ & $\mathbf{- 0 , 6 0 4 9 9 0}$ \\
\hline
\end{tabular}

ronte: Dados da pesquisa, 2019.

A análise dos dados da Tabela 3 revela que a variável V1 (faixa 
etária) apresentou correlação direta, de magnitude fraca, com os indicadores tempo de realização das operações e tempo de estocagem, correlação direta e moderada com o indicador entregas no prazo e correlação negativa e fraca com o indicador desperdícios. Esses resultados sugerem que a faixa etária influencia o uso dos indicadores da dimensão processos internos do BSC de tal modo que quanto maior a faixa etária dos gestores da amostra pesquisada maior é o uso de indicadores relacionados ao tempo de estocagem e entregas no prazo e menor é o uso do indicador desperdícios.

O coeficiente de Spearman também revelou correlação positiva e fraca entre a variável V2 (escolaridade) e os indicadores tempo de estocagem e flexibilidade de volume operacional. Esse resultado sugere que o aumento no nível do ensino formal dos gestores das empresas pesquisadas ocasiona maior uso dos indicadores tempo de estocagem e flexibilidade de volume operacional.

Para a variável V3 (experiência profissional), o coeficiente de Spearman mostrou correlação negativa e fraca com os indicadores flexibilidade de entrega, fornecedores e flexibilidade de volume operacional, além de correlação negativa e moderada com o indicador desperdícios e associação positiva e fraca com os indicadores pós-venda e entregas no prazo. A correlação detectada entre a variável V3 e o indicador de desempenho desperdícios é inversa e tem magnitude moderada. Nesse caso, o resultado da correlação de Spearman sugere que quanto mais o gestor for experiente na vida profissional, menos ele fará uso do indicador de desempenho desperdícios.

Diferente dos resultados encontrados aqui, as pesquisas de Silva, Callado e Callado (2016) e Montenegro e Callado (2019) não demonstraram haver relação entre o uso de indicadores de desempenho da dimensão processos internos do BSC e as características dos gestores.

Finalmente foram investigadas possíveis relações estatisticamente significativas entre o uso de indicadores de desempenho da perspectiva aprendizagem e crescimento e características pessoais dos gestores cujos resultados encontram-se consolidados na Tabela 4.

Tabela 4 - Relações entre uso de indicadores de desempenho 
da perspectiva aprendizagem e crescimento e características dos gestores

\begin{tabular}{|l|l|l|l|}
\hline \multirow{2}{*}{ Indicadores } & \multicolumn{2}{l}{ Correlação } \\
\cline { 2 - 4 } & $\begin{array}{l}\text { Faixa Etária } \\
(\mathrm{V} 1)\end{array}$ & $\begin{array}{l}\text { Escolaridade } \\
(\mathrm{V} 2)\end{array}$ & $\begin{array}{l}\text { Expe- } \\
\text { riência } \\
\text { Profissio- } \\
\text { nal (V3) }\end{array}$ \\
\hline Produtividade dos empregados & $-0,083126$ & 0,054554 & $-0,111392$ \\
\hline Satisfação dos empregados & $-0,087759$ & 0,125988 & 0,114332 \\
\hline Rotatividade de empregados & $-0,019096$ & 0,065795 & 0,009951 \\
\hline Flexibilidade dos empregados & $-0,029088$ & $\mathbf{0 , 3 5 6 3 4 8}$ & $-0,141479$ \\
\hline Inovação nos produtos & $\mathbf{0 , 4 1 6 9 3 0}$ & 0,133631 & 0,202113 \\
\hline Investimentos em treinamento & 0,043879 & 0,125988 & $\mathbf{- 0 , 2 7 4 3 9 8}$ \\
\hline Gestão de risco & 0,076001 & $\mathbf{0 , 2 1 8 2 1 8}$ & $-0,326749$ \\
\hline
\end{tabular}

Fonte: Dados da pesquisa, 2019.

Os resultados demonstraram que a variável V1 (faixa etária) apresentou correlação positiva e moderada com o indicador inovação nos produtos. Já a variável V2 (escolaridade) apresentou correlação positiva e fraca com os indicadores flexibilidade dos empregados e gestão de risco. Por sua vez, a variável V3 (experiência profissional) tem correlação negativa e fraca com os indicadores investimento em treinamento e gestão de risco. Na perspectiva aprendizagem e crescimento, o coeficiente de correlação de Spearman demonstrou haver relações estatisticamente significativas entre o uso de indicadores de desempenho e as características dos gestores pesquisados.

Os resultados aqui encontrados foram corroborados na pesquisa de Montenegro e Callado (2019) a qual evidenciou que as características dos gestores influenciam o uso de indicadores de desempenho da perspectiva aprendizagem e crescimento do BSC.

\subsection{Relações entre uso de indicadores de desempenho e as características das empresas}

Essa seção buscou encontrar possíveis relações estatisticamente significativas entre o uso de indicadores de desempenho associáveis às perspectivas do Balanced Scorecard e as características das empre- 
sas pertencentes ao setor estudado. As características das empresas dizem respeito ao seu ambiente organizacional interno e externo.

Inicialmente foram analisadas as possíveis relações entre o uso de indicadores de desempenho e as características das empresas cujos resultados são apresentados na Tabela 5.

Tabela 5 - Relações entre uso de indicadores de desempenho da perspectiva financeira e características das empresas.

\begin{tabular}{l|l|l|l|l|l}
\hline \multirow{2}{*}{ Indicadores } & \multicolumn{4}{l}{ Correlação } & \multicolumn{4}{l}{$l$} \\
\cline { 2 - 6 } & V4 & V5 & V6 & V7 & V8 \\
\hline Lucratividade & 0,207514 & $-0,103639$ & 0,204056 & $\mathbf{- 0 , 2 5 3 6 2 9}$ & 0,026230 \\
\hline Rentabilidade & $\mathbf{0 , 3 7 9 9 8 0}$ & 0,139168 & $-0,174369$ & $\mathbf{- 0 , 4 6 4 4 2 0}$ & 0,048029 \\
\hline Faturamento & 0,207514 & $-0,103639$ & 0,204056 & $\mathbf{- 0 , 2 5 3 6 2 9}$ & 0,026230 \\
\hline Crescimento das vendas & $-0,082061$ & 0,110657 & $\mathbf{- 0 , 3 0 8 6 5 2}$ & $-0,082061$ & $-0,116690$ \\
\hline Custos totais & $\mathbf{- 0 , 2 5 3 6 2 9}$ & $\mathbf{- 0 , 3 3 1 6 4 6}$ & 0,040811 & 0,207514 & $\mathbf{- 0 , 4 4 5 9 0 4}$ \\
\hline Custos unitários & 0,098513 & $\mathbf{0 , 3 0 3 6 3 9}$ & 0,124549 & $-0,182953$ & 0,048029 \\
\hline Fluxo de caixa & 0,098513 & $-0,025303$ & 0,124549 & $-0,182953$ & 0,048029 \\
\hline Retorno do investimento & 0,031607 & 0,142070 & 0,074593 & $\mathbf{- 0 , 3 8 9 8 1 9}$ & 0,071912 \\
\hline Inventários & 0,492366 & $-0,073771$ & 0,199716 & $\mathbf{- 0 , 3 2 8 2 4 4}$ & $\mathbf{- 0 , 4 9 0 0 9 8}$ \\
\hline Preço dos produtos & $\mathbf{0 , 2 9 0 1 2 9}$ & $\mathbf{0 , 3 7 5 5 8 1}$ & $-0,041082$ & $-\mathbf{- 0 , 1 7 4 0 7 8}$ & 0,066010 \\
\hline Capital de Giro & $-0,082061$ & 0,092214 & 0,000000 & $\mathbf{- 0 , 2 8 7 2 1 3}$ & 0,081683 \\
\hline
\end{tabular}

Onde: V4 - tempo de atuação da empresa; V5 - número de empregados; V6 - formalização de processos operacionais; V7 - prioridade estratégica; e V8 - estrutura hierárquica.

'onte: Dados da pesquisa, 2019.

Nos resultados é possível observar que a variável V4 (tempo de atuação da empresa) está associada de forma negativa, com magnitude fraca, ao indicador custos totais. V4 também apresenta correlação positiva e de magnitude fraca com os indicadores rentabilidade e preço dos produtos, com o indicador inventários a correlação é positiva e moderada. Klein e Almeida (2017) afirmam que quanto maior for o nível de incerteza, maior será a necessidade por informações para lidar com essa incerteza. Nesse tipo de cenário, a informação passa a ser valorizada pelos gestores em função do comportamento destes ser suscetível aos níveis percebidos de incerteza ambiental. Dessa forma, os resultados aqui encontrados sugerem que os ges- 
tores das empresas pesquisadas percebem que as empresas atuam em ambientes de incerteza visto que o uso de poucos indicadores financeiros se mostrou dependente dessa variável.

O porte organizacional pode ser mensurado utilizando-se critérios quantitativos, qualitativos ou uma miscelânea destes. Os critérios quantitativos são critérios econômicos como lucros, valor do capital, ativos, volume de vendas, valorização de ações e número de empregados, os quais dão uma dimensão do porte da organização (CHENHALL, 2007; LEONE, 1991). Nesse sentido, a variável V5 (número de empregados) apresentou correlação positiva e fraca com os indicadores custos unitários e preço dos produtos, e correlação negativa e fraca com o indicador custos totais. Esses resultados sugerem que quanto maior o número de empregados das empresas da amostra pesquisada, mais os gestores tendem a usar os indicadores custos unitários e preços dos produtos, ao passo que quanto menos empregados, os gestores tendem a usar mais o indicador custos totais.

Os resultados demonstraram que a variável V6 (formalização de processos operacionais) aparece correlacionada de forma negativa e magnitude classificada como fraca com o indicador crescimento das vendas. Esse resultado sugere que os gestores da amostra de empresas pesquisadas não associam o crescimento das vendas a um maior nível de formalização dos processos operacionais. Destaque-se que V5 apresentou correlação 0 (zero) com o indicador inventários o que sugere independência do uso desse indicador em relação a essa variável.

Os resultados demonstraram que a variável V7 (prioridade estratégica) apareceu correlacionada de forma negativa e moderada com o indicador rentabilidade e em associação negativa e fraca com os indicadores lucratividade, faturamento, retorno do investimento, inventários e capital de giro.

Conforme os resultados, a variável V8 (estrutura hierárquica) se mostrou relacionada de forma negativa e moderada com os indicadores custos totais e inventários. Este resultado sugere que os gestores das empresas pesquisadas mais hierarquizadas, ou seja, empresas mais descentralizadas, tendem a usar menos os indicadores custos totais e inventários.

Destaque-se que no tocante à relação entre indicadores e as 
características das empresas, este estudo diverge dos resultados obtidos na pesquisa de Silva e Callado (2018) quando não foram encontradas correlações significativas. Esses autores investigaram fatores contingenciais e indicadores de desempenho na indústria da construção civil de João Pessoa/PB.

Em seguida foram analisadas as relações entre o uso de indicadores de desempenho da perspectiva clientes e as características das empresas cujos resultados são apresentados na Tabela 6.

Analisando os resultados é possível observar que a variável V4 (tempo de atuação da empresa) apresenta correlação positiva e fraca com o uso dos indicadores quantidade de clientes, novos clientes, tempo de entrega e crescimento da participação de mercado, além de apresentar associação positiva e moderada com o uso do indicador responsividade.

Tabela 6 - Relações entre uso de indicadores de desempenho da perspectiva clientes e características das empresas.

\begin{tabular}{|c|c|c|c|c|c|}
\hline \multirow[b]{2}{*}{ Indicadores } & \multicolumn{5}{|c|}{ Correlação } \\
\hline & V4 & V5 & V6 & V7 & V8 \\
\hline Quantidade de clientes & 0,212121 & 0,063564 & $-0,375455$ & $-0,393939$ & 0,103418 \\
\hline Novos clientes & 0,287213 & $-0,036886$ & $-0,054468$ & $-0,328244$ & $-0,070014$ \\
\hline Satisfação de clientes & $-0,065795$ & $-0,128155$ & $-0,116458$ & $-0,285112$ & $-0,149696$ \\
\hline Qualidade dos produtos & 0,058026 & $-0,219089$ & $-0,143788$ & $-0,406181$ & $-0,171626$ \\
\hline Devolução de produtos & 0,010101 & 0,481272 & $-0,214546$ & 0,010101 & 0,298762 \\
\hline Tempo de entrega & 0,372839 & 0,197162 & 0,038819 & $-0,504430$ & 0,062373 \\
\hline Pontualidade de entrega & 0,201008 & 0,090351 & $-0,177892$ & $-0,552771$ & $-0,200082$ \\
\hline Responsividade & 0,502519 & 0,234912 & $-0,088946$ & $-0,301511$ & $-0,091466$ \\
\hline $\begin{array}{l}\text { Crescimento da participação de } \\
\text { mercado }\end{array}$ & 0,389819 & 0,435681 & 0,261074 & $-0,242320$ & 0,131838 \\
\hline
\end{tabular}

Onde: V4 - tempo de atuação da empresa; V5 - número de empregados; V6 - formalização de processos operacionais; V7 - prioridade estratégica; e V8 - estrutura hierárquica.

Fonte: Dados da pesquisa, 2019.

Dessa forma, os resultados encontrados sugerem, para a amostra estudada, que quanto maior o tempo de atuação das empresas no mercado, mais os gestores fazem uso de indicadores relacionados 
com a monitoração do relacionamento da empresa com seus clientes.

No que concerne a variável V5 (número de empregados), os resultados apresentaram correlação positiva e fraca com o indicador responsividade, positiva e moderada com os indicadores devolução de produtos e crescimento da participação de mercado, além de apresentar correlação negativa e fraca com o indicador qualidade dos produtos. Os resultados sugerem que quanto maior o número de empregados nas empresas pesquisadas, os gestores tendem a usar mais os indicadores responsividade, devolução de produtos e crescimento da participação de mercado, ao passo que quanto menos empregados, os gestores tendem a usar mais o indicador qualidade dos produtos.

Estes resultados podem ser explicados, em parte, pela afirmativa de Chenhall (2007) quando diz que à medida que as organizações se tornam maiores, aumenta a necessidade de lidar com grandes quantidades de informações o que acarreta a instituição de controles como regras, documentação, especialização de papéis e funções, hierarquias ampliadas e maior descentralização de estruturas hierárquicas.

Nos achados da pesquisa, a variável V6 (formalização de processos operacionais) aparece correlacionada de forma negativa e fraca com os indicadores quantidade de clientes e devolução de produtos, além de apresentar associação positiva e fraca com o indicador crescimento da participação de mercado. Estes resultados sugerem que quanto mais completos e formais estiverem os processos operacionais, mais os gestores das empresas pesquisadas se preocupam com o crescimento da participação das empresas no mercado ao passo que dão menor ênfase a quantidade de clientes e a devolução de produtos.

A partir dos resultados da Tabela 6 é possível observar que a variável V7 (prioridade estratégica) apresentou correlação negativa e moderada com os indicadores qualidade dos produtos, tempo de entrega e pontualidade de entrega. Essa mesma variável apareceu em associação negativa e fraca com os indicadores quantidade de clientes, novos clientes, satisfação de clientes, responsividade e crescimento da participação de mercado. Estes achados para a variável V7 sugerem que os gestores das empresas pesquisadas ao adotarem uma prioridade estratégica diminuem o uso dos indicadores cor- 
relacionados de forma negativa com essa variável. Os resultados aqui encontrados divergem da pesquisa de Hoque (2004), o qual encontrou uma associação significativa e positiva entre a estratégia e o uso pela administração de medidas não financeiras para avaliação de desempenho.

Ainda de acordo com os resultados, a variável V8 (estrutura hierárquica) se mostrou relacionada de forma positiva e fraca com o indicador devolução de produtos. Este resultado sugere que quanto mais descentralizadas são as empresas pesquisadas, mais os gestores fazem uso do indicador devolução de produtos.

Do mesmo modo foram pesquisadas as relações entre o uso de indicadores de desempenho da perspectiva processos internos e as características das empresas cujos resultados são apresentados na Tabela 7 .

Tabela 7 - Relações entre uso de indicadores de desempenho da perspectiva processos internos e características das empresas.

\begin{tabular}{|c|c|c|c|c|c|}
\hline \multirow[b]{2}{*}{ Indicadores } & \multicolumn{5}{|l|}{ Correlação } \\
\hline & V4 & V5 & V6 & V7 & V8 \\
\hline Tempo de realização das operações & $-0,191919$ & $-0,372304$ & $-0,268182$ & $-0,191919$ & $-0,114908$ \\
\hline Flexibilidade de entrega & $-0,058026$ & $-0,104328$ & $-0,513530$ & $-0,058026$ & $-0,052808$ \\
\hline Tempo de estocagem & 0,301511 & $-0,022588$ & $-0,289075$ & $-0,201008$ & $-0,042875$ \\
\hline Fornecedores & 0,058026 & $-0,104328$ & 0,000000 & 0,058026 & 0,066010 \\
\hline $\begin{array}{l}\text { Flexibilidade de volume operacio- } \\
\text { nal }\end{array}$ & 0,050252 & $-0,169408$ & $-0,088946$ & $-0,201008$ & $-0,057166$ \\
\hline Uso da capacidade instalada & 0,065795 & $-0,483046$ & $-0,194096$ & $-0,372839$ & $-0,498987$ \\
\hline Pós-venda & $-0,285112$ & 0,088723 & $-0,504650$ & 0,153522 & 0,074848 \\
\hline Entregas no prazo & 0,098513 & $-0,164471$ & $-0,174369$ & $-0,464420$ & $-0,240146$ \\
\hline Desperdícios & $-0,065795$ & $-0,256310$ & $-0,019410$ & 0,372839 & $-0,149696$ \\
\hline
\end{tabular}

Onde: V4 - tempo de atuação da empresa; V5 - número de empregados; V6 - formalização de processos operacionais; V7 - prioridade estratégica; e V8 - estrutura hierárquica.

'onte: Dados da pesquisa, 2019.

Os resultados evidenciaram que a variável V4 (Tempo de atuação da empresa) apresentou associação positiva com o indicador tempo de estocagem e relação negativa com o indicador pós-venda. 
Nas duas situações, a correlação apresentou magnitude fraca. (Estes resultados sugerem que quanto maior o tempo de mercado da empresa, mais os gestores usam o indicador tempo de estocagem e menos utilizam o indicador pós-venda. Este segundo resultado pode ser interpretado levando-se em consideração que empresas com maior tempo de mercado já estão com seus processos internos plenamente formalizados, o que pode acarretar menor monitoração das atividades de pós-venda.

A variável V5 (número de empregados) apresentou correlação negativa e fraca com os indicadores tempo de realização das operações e desperdícios, além de correlação negativa e moderada com o indicador uso da capacidade instalada. Estes resultados sugerem que para as empresas pesquisadas, quanto maior o número de empregados, os gestores tendem a usar menos os indicadores com os quais a variável mantém correlação negativa.

A variável V6 (formalização de processos operacionais) apresentou correlação negativa e moderada com os indicadores flexibilidade de entrega e pós-venda, além de associação de forma negativa e fraca com os indicadores tempo de realização das operações e tempo de estocagem. Estes resultados sugerem que os gestores das empresas da amostra pesquisada ao perceberem melhorias no nível de formalização dos processos operacionais usam menos os indicadores supracitados. Esses resultados podem ser interpretados à luz do que afirma Guerra (2007), quando diz que não se pode negar a presença da tecnologia como um fator interno à organização, pois os instrumentos e processos tecnológicos adotados para realizar o trabalho de produção afetam a estrutura, os sistemas de informações e demais componentes internos à organização.

De acordo com os resultados, a variável V7 (prioridade estratégica) apresentou correlação negativa e moderada com o indicador entregas no prazo, associação negativa e fraca com o indicador uso da capacidade instalada, além de correlação positiva e fraca com o indicador desperdícios. Esses resultados sugerem que a prioridade estratégica influencia o uso de indicadores de desempenho nas empresas pesquisadas. Nesse sentido Chenhall (2007) afirma que as pesquisas reconhecem que os gerentes têm uma "escolha estratégica" na qual podem posicionar suas organizações em ambientes 
específicos.

O resultado dos testes ainda demonstrou que a variável V8 (estrutura hierárquica) se apresentou correlacionada de forma negativa e moderada com o indicador uso da capacidade instalada e associada de maneira negativa e fraca ao indicador entregas no prazo. Este resultado sugere que as empresas com mais níveis hierárquicos usam menos os indicadores uso da capacidade instalada e entregas no prazo.

Em seguida foram analisadas as relações entre o uso de indicadores de desempenho da perspectiva aprendizagem e crescimento e características das empresas cujos resultados são apresentados na Tabela 8 .

Tabela 8 - Relações entre uso de indicadores de desempenho da perspectiva aprendizagem e crescimento e as características das empresas.

\begin{tabular}{|c|c|c|c|c|c|}
\hline \multirow[b]{2}{*}{ Indicadores } & \multicolumn{5}{|c|}{ Correlação } \\
\hline & V4 & V5 & V6 & V7 & V8 \\
\hline Produtividade dos empregados & $-0,050252$ & $-0,180702$ & $-0,177892$ & $-0,050252$ & $-0,200082$ \\
\hline Satisfação dos empregados & 0,058026 & $-0,219089$ & $-0,472448$ & $-0,406181$ & $-0,171626$ \\
\hline Rotatividade de empregados & 0,191919 & $-0,345063$ & 0,017879 & $-0,414141$ & $-0,287271$ \\
\hline Flexibilidade dos empregados & 0,082061 & 0,027664 & $-0,254184$ & $-0,328244$ & $-0,081683$ \\
\hline Inovação nos produtos & 0,082061 & 0,027664 & $-0,308652$ & $-0,328244$ & $-0,081683$ \\
\hline Investimentos em treinamento & $-0,174078$ & $-0,469476$ & $-0,287577$ & $-0,406181$ & $-0,409261$ \\
\hline Gestão de risco & 0,301511 & $-0,198772$ & $-0,088946$ & $-0,100504$ & $-0,308697$ \\
\hline
\end{tabular}

Onde: V4 - tempo de atuação da empresa; V5 - número de empregados; V6 - formalização de processos operacionais; V7 - prioridade estratégica; e V8 - estrutura hierárquica.

Fonte: Dados da pesquisa, 2019.

A variável V4 (Tempo de atuação da empresa) apresentou correlação positiva e fraca com o indicador gestão de risco. Para Guerra (2007), cada organização assume uma percepção ambiental conforme as experiências, expectativas, convicções e formas de pensar dos seus membros. Dessa forma, o resultado aqui encontrado sugere que maior tempo de atuação da empresa no mercado pode influenciar a utilização de indicadores de desempenho relacionados à tomada de decisão, como a gestão de risco.

A variável V5 (número de empregados) apresentou correlação 
negativa e fraca com os indicadores satisfação dos empregados e rotatividade dos empregados, além de correlação negativa e moderada com o indicador investimentos em treinamento. Esses resultados sugerem que nas empresas pesquisadas, quanto maior o número de empregados, os gestores tendem a usar menos os indicadores com os quais a variável mantém correlação negativa.

De acordo com os resultados obtidos, a variável V6 (formalização de processos operacionais) está correlacionada negativamente e com magnitude moderada com o indicador satisfação dos empregados e em correlação negativa e fraca com os indicadores flexibilidade dos empregados, inovação nos produtos e investimentos em treinamento. Esses resultados sugerem que nas empresas pesquisadas, os gestores ao perceberem aumentos no nível de formalização dos processos operacionais, eles reduzem o uso dos indicadores supracitados. Este comportamento talvez não seja o mais indicado visto que a satisfação dos colaboradores pode estar associada à produtividade dos mesmos e sua não observância pode gerar impactos negativos nos resultados da empresa.

De acordo com os resultados a variável V7 (prioridade estratégica) apresentou correlação negativa e moderada com os indicadores satisfação dos empregados, rotatividade dos empregados e investimentos em treinamento, e associação negativa e fraca com os indicadores flexibilidade dos empregados e inovação nos produtos. Esses resultados sugerem que os gestores das empresas pesquisadas ao adotarem uma prioridade estratégica para a empresa, diminuem o uso dos indicadores correlacionados de forma negativa com a variável $\mathrm{V7}$. O comportamento evidenciado nos testes pode impactar o resultado das empresas, visto que essa perspectiva engloba indicadores que visam monitorar a situação de bem-estar dos empregados, o que pode gerar interferência sobre a produtividade dos mesmos.

A variável V8 (estrutura hierárquica) se apresentou correlacionada de forma negativa e moderada com o indicador investimentos em treinamento e relacionada de maneira negativa e fraca aos indicadores rotatividade de empregados e gestão de risco. Esse resultado sugere que as empresas com mais níveis hierárquicos usam menos os indicadores rotatividade dos empregados, investimentos em treinamento e gestão de risco, ou seja, as empresas menos centralizadas estão menos preocupadas com a gestão de riscos.

Destaque-se que, embora o uso do indicador produtividade dos 
empregados não tenha se mostrado influenciado por qualquer das variáveis, Parizi, Naas e Garcia (2017), afirmam que a produtividade pode ser afetada por diversos fatores de natureza externa ou por fatores internos. Segundo pesquisa dessas autoras, os fatores que mais afetaram negativamente a produtividade foram: falta de capacitação e treinamento; insatisfação do trabalhador; falta de compromisso organizacional; e falta de compromisso com a qualidade.

\subsection{Relações entre uso de indicadores de desempenho e as características da mensuração de desempenho}

Essa seção buscou encontrar possíveis relações estatisticamente significativas entre o uso de indicadores de desempenho associáveis às perspectivas do BSC e as características da mensuração de desempenho.

Inicialmente foram analisadas as relações entre o uso de indicadores de desempenho da perspectiva financeira e as características da mensuração de desempenho cujos resultados são apresentados na Tabela 9.

Tabela 9 - Relações entre uso de indicadores de desempenho da perspectiva financeira e as características da mensuração de desempenho

\begin{tabular}{l|l|l|l}
\hline \multirow{2}{*}{ Indicadores } & \multicolumn{2}{l}{ Correlação } & \\
\cline { 2 - 4 } & V9 & V10 & V11 \\
\hline Lucratividade & $-0,176604$ & 0,198680 & $\mathbf{0 , 3 0 0 0 4 6}$ \\
\hline Rentabilidade & $\mathbf{- 0 , 4 5 8 1 2 3}$ & 0,040423 & $\mathbf{0 , 2 8 1 7 5 2}$ \\
\hline Faturamento & $-0,176604$ & 0,198680 & $\mathbf{0 , 3 0 0 0 4 6}$ \\
\hline Crescimento das vendas & $-0,098209$ & $\mathbf{- 0 , 4 4 1 9 4 2}$ & $\mathbf{- 0 , 2 3 6 1 6 4}$ \\
\hline Custos totais & $\mathbf{- 0 , 3 9 7 3 6 0}$ & $\mathbf{- 0 , 3 3 1 1 3 3}$ & $-0,138483$ \\
\hline Custos unitários & 0,026948 & $\mathbf{0 , 3 6 3 8 0 3}$ & 0,014088 \\
\hline Fluxo de caixa & $-0,080845$ & 0,040423 & 0,014088 \\
\hline Retorno do investimento & $-0,020174$ & 0,090784 & $-0,042185$ \\
\hline Inventários & $\mathbf{- 0 , 4 3 2 1 2 1}$ & 0,000000 & $\mathbf{0 , 2 3 6 1 6 4}$ \\
\hline Preço dos produtos & $-0,044444$ & 0,066667 & $-0,127786$ \\
\hline Capital de Giro & $-0,196419$ & 0,176777 & 0,092412 \\
\hline Onde: V9 - cinterio adotado para a seleçăo
\end{tabular}

Onde: V9 - critério adotado para a seleção dos indicadores de desempenho; V10 procedimentos referentes à mensuração de desempenho no âmbito da empresa; e V11 - frequência dos relatórios sobre desempenho.

${ }^{7}$ Oonte: Dados da pesquisa, 2019.

O resultado do teste apresentou a variável V9 (critério adotado 
para a seleção dos indicadores de desempenho) correlacionada de forma negativa e moderada com os indicadores rentabilidade e inventários e associada de maneira negativa e fraca com o indicador custos totais. Essa relação inversa indica que o aprimoramento dos critérios adotados para selecionar os indicadores de desempenho reduz o uso dos indicadores rentabilidade, custos totais e inventários, na amostra de empresas pesquisadas.

A variável V10 (procedimentos referentes à mensuração de desempenho no âmbito da empresa) se apresentou correlacionada de maneira negativa e moderada com o indicador crescimento das vendas, negativa e fraca com o indicador custos totais e positiva e fraca com o indicador custos unitários. Esse resultado sugere que à medida que ocorre a evolução dos procedimentos referentes à mensuração de desempenho, as empresas investigadas fazem mais uso do indicador custos unitários e reduzem o uso dos indicadores crescimento das vendas e custos totais.

A variável V11 apresentou correlação positiva e fraca com os indicadores lucratividade, rentabilidade, faturamento e inventários, além de correlação negativa e fraca com o indicador crescimento das vendas. Esses resultados sugerem que nas empresas pesquisadas, quanto mais aumenta a frequência dos relatórios sobre desempenho, os gestores tendem a usar mais os indicadores lucratividade, rentabilidade, faturamento e inventários e tendem a usar menos o indicador crescimento das vendas.

Diferente dos resultados encontrados aqui, a pesquisa desenvolvida por Montenegro e Callado (2019) não demonstrou haver correlação entre o uso de indicadores de desempenho da dimensão financeira do BSC e as características da mensuração de desempenho adotadas pelas empresas pesquisadas.

Em seguida foram pesquisadas as relações estatisticamente significativas entre o uso de indicadores de desempenho da perspectiva clientes e os fatores relacionados à mensuração de desempenho cujos resultados são apresentados na Tabela 10.

Tabela 10 - Relações entre uso de indicadores de desempenho da 
perspectiva clientes e as características da mensuração de desempenho

\begin{tabular}{l|l|l|l}
\hline \multirow{2}{*}{ Indicadores } & \multicolumn{3}{l}{ Correlação } \\
\cline { 2 - 4 } & V9 & V10 & V11 \\
\hline Quantidade de clientes & $-0,270787$ & $\mathbf{- 0 , 2 9 0 1 2 9}$ & 0,091001 \\
\hline Novos clientes & $-0,157135$ & 0,058926 & 0,102680 \\
\hline Satisfação de clientes & $\mathbf{- 0 , 2 3 0 9 7 8}$ & $\mathbf{- 0 , 2 5 1 9 7 6}$ & 0,087816 \\
\hline Qualidade dos produtos & $\mathbf{- 0 , 3 5 5 5 5 6}$ & $-0,100000$ & $\mathbf{0 , 3 1 3 6 5 7}$ \\
\hline Devolução de produtos & $-0,096710$ & $-0,058026$ & $-0,101112$ \\
\hline Tempo de entrega & $-0,230978$ & 0,157485 & $\mathbf{0 , 2 3 0 5 1 6}$ \\
\hline Pontualidade de entrega & $\mathbf{- 0 , 2 8 8 6 7 5}$ & $-0,036084$ & 0,176060 \\
\hline Responsividade & $\mathbf{- 0 , 3 4 6 4 1 0}$ & 0,202073 & 0,160969 \\
\hline Crescimento da participação de mercado & $\mathbf{0 , 3 0 2 6 1 4}$ & $\mathbf{0 , 2 4 2 0 9 1}$ & $-0,158195$ \\
\hline
\end{tabular}

Onde: V9 - critério adotado para a seleção dos indicadores de desempenho; V10 procedimentos referentes à mensuração de desempenho no âmbito da empresa; e V11 - frequência dos relatórios sobre desempenho.

${ }^{7}$ Onte: Dados da pesquisa, 2019.

Os resultados apontaram que a variável V9 (critério adotado para a seleção dos indicadores de desempenho) apresentou correlação positiva e fraca com o indicador crescimento da participação de mercado, e correlação negativa e fraca com os indicadores quantidade de clientes, satisfação de clientes, qualidade dos produtos, tempo de entrega, pontualidade de entrega e responsividade. Esses resultados sugerem que nas empresas pesquisadas, a medida que evoluem os critérios para a escolha dos indicadores de desempenho, os gestores tendem a usar mais o indicador crescimento da participação de mercado e a usar menos os indicadores com os quais a variável V9 apresentou correlação negativa.

Após os testes, a variável V10 (procedimentos referentes à mensuração de desempenho no âmbito da empresa) se mostrou correlacionada de forma negativa e fraca com os indicadores quantidade de clientes e satisfação de clientes, além de associação positiva e fraca com o indicador crescimento da participação de mercado. Esse resultado sugere que quanto mais alinhados estiverem os procedimentos referentes à mensuração de desempenho, mais as empresas da amostra de pesquisa farão uso do indicador crescimento da participação de mercado e reduzirão o uso dos indicadores quantidade de clientes e satisfação de clientes.

Com relação a variável V11 (frequência dos relatórios sobre 
desempenho), esta apresentou correlação positiva e fraca com os indicadores qualidade dos produtos e tempo de entrega. Esses resultados sugerem que as empresas pesquisadas, quanto mais aumentam a frequência de emissão dos relatórios sobre desempenho, tendem a usar mais os indicadores qualidade dos produtos e tempo de entrega, fatores que impactam indiretamente os resultados, pois estão relacionados com a qualidade dos serviços e produtos ofertados.

A pesquisa desenvolvida por Montenegro e Callado (2019) não evidenciou correlação significativa entre o uso de indicadores de desempenho da dimensão clientes do BSC e as características da mensuração de desempenho, resultados divergentes dos aqui evidenciados quando o uso dos indicadores da perspectiva clientes se mostraram influenciados pelas características da mensuração de desempenho.

Em seguida foram pesquisadas as relações entre o uso de indicadores de desempenho da perspectiva processos internos e os fatores relacionados à mensuração de desempenho cujos resultados estão dispostos na Tabela 11.

Tabela 11 - Relações entre uso de indicadores de desempenho da perspectiva processos internos e as características da mensuração de desempenho

\begin{tabular}{|l|c|c|c|}
\hline \multirow{2}{*}{ Indicadores } & \multicolumn{3}{c|}{ Correlação } \\
\cline { 2 - 4 } & V9 & \multicolumn{1}{c|}{ V10 } & \multicolumn{1}{c|}{ V11 } \\
\hline Tempo de realização das operações & $\mathbf{- 0 , 2 7 0 7 8 7}$ & $\mathbf{- 0 , 2 9 0 1 2 9}$ & $\mathbf{0 , 2 2 2 4 4 7}$ \\
\hline Flexibilidade de entrega & $\mathbf{- 0 , 5 5 5 5 5 6}$ & $\mathbf{- 0 , 3 3 3 3 3 3}$ & 0,127786 \\
\hline Tempo de estocagem & $\mathbf{- 0 , 4 8 1 1 2 5}$ & $\mathbf{- 0 , 2 5 2 5 9 1}$ & 0,062878 \\
\hline Fornecedores & $-0,155556$ & $\mathbf{0 , 2 3 3 3 3 3}$ & $\mathbf{0 , 3 1 3 6 5 7}$ \\
\hline Flexibilidade de volume operacional & $\mathbf{- 0 , 2 6 4 6 1 9}$ & $\mathbf{- 0 , 2 5 2 5 9 1}$ & $\mathbf{0 , 3 0 1 8 1 6}$ \\
\hline Uso da capacidade instalada & $\mathbf{- 0 , 4 4 0 9 5 9}$ & $\mathbf{- 0 , 4 0 9 4 6 2}$ & $\mathbf{0 , 3 9 5 1 7 0}$ \\
\hline Pós-venda & $\mathbf{- 0 , 2 3 0 9 7 8}$ & $\mathbf{- 0 , 3 4 6 4 6 7}$ & 0,087816 \\
\hline Entregas no prazo & $\mathbf{- 0 , 3 2 3 3 8 1}$ & $-0,161690$ & $\mathbf{0 , 2 8 1 7 5 2}$ \\
\hline Desperdícios & $\mathbf{- 0 , 2 3 0 9 7 8}$ & $-0,094491$ & 0,021954 \\
\hline
\end{tabular}

Onde: V9 - critério adotado para a seleção dos indicadores de desempenho; V10 - procedimentos referentes à mensuração de desempenho no âmbito da empresa; e V11 - frequência dos relatórios sobre desempenho.

Гonte: Dados da pesquisa, 2019. 
a seleção dos indicadores de desempenho) apresentou correlação negativa e fraca com os indicadores tempo de realização das operações, flexibilidade de volume operacional, pós-venda, entregas no prazo e desperdícios, e apresentou correlação negativa e moderada com os indicadores flexibilidade de entrega, tempo de estocagem e uso da capacidade instalada. Esses resultados sugerem que as empresas pesquisadas, quanto mais são criteriosas na escolha dos indicadores de desempenho, tendem a usar menos os indicadores da dimensão processos internos com os quais a variável V9 apresentou correlação negativa.

No que tange a variável V10 (procedimentos referentes à mensuração de desempenho no âmbito da empresa), esta se mostrou associada de forma negativa e fraca com os indicadores tempo de realização das operações, flexibilidade de entrega, tempo de estocagem, flexibilidade de volume operacional e pós-venda, além de apresentar associação negativa e moderada com o indicador uso da capacidade instalada e positiva e fraca com o indicador fornecedores. Esses resultados sugerem que quanto mais estruturados forem os procedimentos referentes à mensuração de desempenho, as empresas da amostra pesquisada fazem mais uso do indicador fornecedores e reduzem o uso dos indicadores significativamente relacionados com a mencionada variável.

Com relação a variável V11 (frequência dos relatórios sobre desempenho), o resultado do teste demonstrou correlação positiva e fraca com os indicadores tempo de realização das operações, fornecedores, flexibilidade de volume operacional, uso da capacidade instalada e entregas no prazo. Esses resultados sugerem que nas empresas investigadas, à medida que aumenta a frequência dos relatórios de desempenho, mais os gestores utilizam os indicadores para acompanhar o desempenho das atividades operacionais.

O resultado aqui encontrado, com relação à variável frequência dos relatórios sobre desempenho, concorda parcialmente com o resultado da pesquisa conduzida por Silva, Callado e Callado (2016). Na pesquisa desses autores foi evidenciada relação da variável supracitada com o indicador flexibilidade de volume operacional. A pesquisa aqui conduzida também encontrou relação entre a variável frequência dos relatórios sobre desempenho e o indicador flexibilida- 
de de volume operacional. Com relação à pesquisa de Montenegro e Callado (2019), os resultados divergem totalmente visto que o estudo desses autores não evidenciou correlação significativa entre o uso de indicadores de desempenho da dimensão processos internos e as características da mensuração de desempenho.

Por fim foram analisadas as relações estatisticamente significativas entre o uso de indicadores de desempenho da perspectiva aprendizagem e crescimento e os fatores relacionados à mensuração de desempenho cujos resultados estão na Tabela 12.

Tabela 12 - Relações entre uso de indicadores de desempenho da perspectiva aprendizagem e crescimento e as características da mensuração de desempenho

\begin{tabular}{|l|l|l|l}
\hline \multirow{2}{*}{ Indicadores } & \multicolumn{2}{l}{ Correlação } \\
\cline { 2 - 4 } & V9 & V10 & V11 \\
\hline Produtividade dos empregados & $\mathbf{- 0 , 5 0 5 1 8 1}$ & $-0,036084$ & 0,414998 \\
\hline Satisfação dos empregados & $\mathbf{- 0 , 3 5 5 5 5 6}$ & $-0,200000$ & $\mathbf{0 , 3 1 3 6 5 7}$ \\
\hline Rotatividade de empregados & $-0,174078$ & $-0,029013$ & $\mathbf{0 , 2 9 3 2 2 6}$ \\
\hline Flexibilidade dos empregados & $\mathbf{- 0 , 6 0 8 8 9 8}$ & $-0,088388$ & 0,041072 \\
\hline Inovação nos produtos & $\mathbf{- 0 , 4 3 2 1 2 1}$ & $\mathbf{- 0 , 3 2 4 0 9 1}$ & $-0,092412$ \\
\hline Investimentos em treinamento & $-0,666667$ & $-0,366667$ & 0,313657 \\
\hline Gestão de risco & $-0,442635$ & $-0,259808$ & 0,352119 \\
\hline
\end{tabular}

Onde: V9 - critério adotado para a seleção dos indicadores de desempenho; V10 procedimentos referentes à mensuração de desempenho no âmbito da empresa; e V11 - frequência dos relatórios sobre desempenho.

'onte: Dados da pesquisa, 2019.

De acordo com os resultados, a variável V9 (critério adotado para a seleção dos indicadores de desempenho) apresentou correlação negativa e fraca com o indicador satisfação dos empregados, correlação negativa e moderada com os indicadores produtividade dos empregados, inovação nos produtos e gestão de risco, além de apresentar correlação negativa e forte com os indicadores investimentos em treinamento e flexibilidade dos empregados. Esses resultados sugerem que nas empresas pesquisadas, quanto mais estas são criteriosas na escolha dos indicadores de desempenho, tendem a usar menos os indicadores com os quais a variável V9 apresentou 
correlação negativa.

Nos resultados foi possível observar que a variável V10 (procedimentos referentes à mensuração de desempenho no âmbito da empresa) se associou de forma negativa e fraca com os indicadores inovação nos produtos, investimentos em treinamento e gestão de risco. Desse modo, os resultados encontrados sugerem que uma evolução registrada nos procedimentos referentes à mensuração de desempenho ocasiona redução do uso de indicadores relacionados a inovação dos produtos, investimentos em treinamento e gestão de risco. O resultado aqui encontrado, com relação à variável procedimentos referentes à mensuração de desempenho, concorda parcialmente com o resultado da pesquisa conduzida por Montenegro e Callado (2019). Na pesquisa desses autores foi evidenciada relação da variável supracitada com o indicador investimentos em treinamento, correlação também aqui verificada.

Já em relação a variável V11 (frequência dos relatórios sobre desempenho), o resultado do teste demonstrou correlação positiva e moderada com o indicador produtividade dos empregados e associação positiva e fraca com os indicadores satisfação dos empregados, rotatividade de empregados, investimentos em treinamento e gestão de risco. Esses resultados sugerem que se aumentando a frequência dos relatórios sobre desempenho, aumentará o uso dos indicadores relacionados à produtividade dos empregados, à satisfação dos empregados, à rotatividade de empregados, aos investimentos em treinamento e à gestão de risco. Os resultados aqui encontrados, com relação à variável frequência dos relatórios sobre desempenho, convergem totalmente com o resultado da pesquisa realizada por Silva, Callado e Callado (2016). Todas as relações evidenciadas na pesquisa desses autores, com relação à variável frequência dos relatórios de desempenho também foram encontradas na pesquisa aqui conduzida.

\section{Conclusão}

A pesquisa que originou este artigo foi produzida com o objetivo de identificar a associação entre uso de indicadores de desempenho associáveis às perspectivas do Balanced Scorecard (BSC) e fatores contingenciais em empresas de construção civil da cidade do Recife. Para atingir o objetivo utilizou-se a análise de frequência 
e o teste não paramétrico coeficiente de correlação de Spearman. Os resultados obtidos com a aplicação do supracitado teste associado ao critério de interpretação da magnitude da correlação de Franzblau (1958) demonstraram a presença de algumas relações estatisticamente significativas.

No que concerne às correlações entre o uso dos indicadores de desempenho e as características dos gestores o teste evidenciou que na perspectiva financeira a característica dos gestores que mais se relacionou com o uso de indicadores de desempenho foi faixa etária. Na perspectiva clientes, o uso dos indicadores de desempenho se mostrou mais influenciado pelo nível de escolaridade e pela experiência profissional do gestor. Na perspectiva processos internos, a experiência do gestor foi quem mais se relacionou com o uso de indicadores daquela dimensão. E por fim, na perspectiva aprendizagem e crescimento, as características dos gestores que mais se associaram com o uso de indicadores de desempenho foram o nível de escolaridade e a experiência profissional.

Ao final da análise das relações envolvendo o uso de indicadores de desempenho das perspectivas do BSC e as características dos gestores, restou evidenciado que o resultado da aplicação do coeficiente de correlação de Spearman revelou haver relação entre as características dos gestores e o uso dos indicadores de desempenho associáveis às quatro perspectivas do BSC. Dessa forma, os resultados encontrados sugerem influência das características dos gestores no uso dos indicadores de desempenho.

As relações entre o uso de indicadores de desempenho e as características das empresas também foram pesquisadas. Dessa forma foram analisadas as relações entre o uso de indicadores e os fatores contingenciais internos e externos. Na perspectiva financeira, no que tange aos relacionamentos estatisticamente significativos, a variável V7 (prioridade estratégica) foi identificada como a mais relacionável por ter apresentado maior quantidade de valores significativos de coeficientes de correlação com os indicadores da perspectiva. $\mathrm{Na}$ dimensão clientes a variável V7 (prioridade estratégica) também foi a que mais se relacionou com o uso dos indicadores de desempenho. No tocante à perspectiva processos internos, a variável V6 (formalização de processos operacionais) foi a que mais influenciou 
o uso de indicadores de desempenho. Na perspectiva aprendizagem e crescimento a variável que mais apareceu relacionada ao uso de indicadores de desempenho foi V7 (prioridade estratégica).

Por fim foram analisadas as relações entre o uso de indicadores de desempenho e as características da mensuração de desempenho organizacional. As características da mensuração de desempenho também foram analisadas com o objetivo de saber se estas exercem influência no uso dos indicadores de desempenho. Na perspectiva financeira, a variável que mais se relacionou com os indicadores da perspectiva financeira foi V11 (frequência dos relatórios sobre desempenho). Na perspectiva clientes, na perspectiva processos internos e na aprendizagem e crescimento, a variável que apareceu mais relacionável com os indicadores de desempenho foi V9 (critério adotado para a seleção dos indicadores de desempenho).

Diante dos resultados dos testes de correlação de Spearman, bem como com as análises realizadas nos dados coletados nas empresas da amostra da pesquisa é possível sugerir que existem associações entre o uso de indicadores de desempenho associáveis as perspectivas do BSC e os fatores contingenciais.

Como limitação ao desenvolvimento desta pesquisa tem-se a dificuldade de acesso à amostra, logo se trata de uma amostra obtida por conveniência. $\mathrm{O}$ tamanho da amostra também é uma limitação visto que, pelo fato de se trabalhar com uma amostra reduzida torna-se inviável fazer inferências, ficando os resultados restritos ao grupo de empresas pesquisado. Como sugestões para futuras pesquisas sugere-se estudos mais aprofundados e em outras regiões com o fito de gerar informações mais detalhadas sobre a natureza das relações encontradas nesta pesquisa.

\section{REFERÊNCIAS}

ABDEL-KADER, M.; LUTHER, R. The impact of firm characteristics on management accounting practices: a UK-based empirical analysis. The British Accounting Review, v. 40, n. 1, p. 2-27, 2008.

ARAÚJO, J. G. R.; CALLADO, A. L. C.; CAVALCANTI, B. S. B. Habilidades e competências do controller: Um estudo com alunos de cursos de pós-graduação em controladoria. Revista Catarinense da Ciência Contábil, v. 13, n. 38, pág. 52-64, 2014.

BARROS, A. A.; LIBONATI, J. J.; BARBOSA, A. M. R. Investigação da produção cientifica sobre 
avaliação de desempenho organizacional no congresso de controladoria e Contabilidade da Universidade de São Paulo - USP. In: Encontro Norte-Rio-Grandense de Ciências Contábeis - ENCC, 9, 2012, Natal. Anais ... Rio Grande do Norte: ENCC, 2012.

BEUREN, I. M.; FIORENTIN, M. Influência de fatores contingenciais nos atributos do Sistema de Contabilidade Gerencial: um estudo em empresas têxteis do Estado do Rio Grande do Sul. Revista de Ciências da Administração, v. 16, n. 38, p. 195-212, 2014.

BRASIL. Ministério do Trabalho e Emprego. Programa de Disseminação das Estatísticas do Trabalho. Relação Anual de Informações Sociais (RAIS). Brasília, DF, 2016.

CAlladO, A. L. C.; CALlADO, A. A. C.; HOLANDA, F. M. A.; LEITÃO, C. R. S. Utilização de indicadores de desempenho no setor hoteleiro de João Pessoa - PB. Revista Turismo Visão e Ação, v. 10, n. 1, pág. 23-38, 2008.

CAllado, A. A. C.; CHAVES, R. P.; CALLADO, A. L. C. Relações entre o uso de indicadores de desempenho de cadeia de suprimento e estrutura administrativa. In: CONGRESSO BRASILEIRO DE CUSTOS, 21, 2014, Natal. Anais ... Rio Grande do Norte: CBC, 2014.

CERVO, A. L.; BERVIAN, P. A.; SILVA, R. Metodologia cienífica. 6. Ed. São Paulo: Pearson Prentice Hall, 2007.

CHENHALL, R. H. Theorizing contingencies in management control systems research. Handbook of Management Accounting Research, v. 1, p. 163-205, 2007.

DONALDSON, L. Structural contingency theory. International Encyclopedia of the Social \& Behavioral Sciences, v. 23, 2. Ed, p. 609-614, 2015.

FERREIRA, H.; CASSIOLATO, M.; GONZALEZ, R. Uma experiência de desenvolvimento metodológico para avaliação de programas: o modelo lógico do programa segundo tempo. Texto para discussão 1369. Brasília: IPEA, 2009.

FRANCISCHINI, P. G.; FRANCISCHINI, A. S. N. Indicadores de desempenho: dos objetivos à ação - métodos para elaborar KPIs e obter resultados. Rio de Janeiro: Alta Books, 2017.

GUERRA, A. R. Arranjos entre fatores situacionais e sistema de contabilidade gerencial sob a ótica da teoria da contingência. 2007. 136 f. Dissertação (Mestrado em Controladoria e Contabilidade: Contabilidade) - Faculdade de Economia, Administração e Contabilidade, Universidade de São Paulo, São Paulo, 2007.

GIL, A. C. Como elaborar projetos de pesquisa. 4. Ed. São Paulo: Atlas, 2008.

HOLANDA, F. M. A. Indicadores de desempenho: uma análise nas empresas de construção civil do município de João Pessoa - PB, 2007. 106 f. Dissertação de Mestrado (Programa Multi-institucional e Inter-regional de Pós-graduação em Ciências Contábeis) - UnB - UFPE - UFPB -UFRN, 2007.

HOQUE, Z. A contingency model of the association between strategy, environmental uncertainty and performance measurement: impact on organizational performance. International Business Review, v. 13, n. 4, p. 485-502, 2004.

INSTITUTO BRASILEIRO DE GEOGRAFIA E ESTATÍSTICA (IBGE). Pesquisa anual da indústria da construção - PAIC, v. 25, p. 1 - 52, 2015. 
KAPLAN, R. S.; NORTON, D. P. A estratégia em ação - balanced scorecard. 43. Ed. Tradução de Luiz Euclides Trindade Frazão Filho. Rio de Janeiro: Campus, 1997.

KENNERLEY, M.; NEELY, A. A framework of the factors affecting the evolution of performance measurement systems. International Journal of Operations \& Production Management, v. 22, n. 11, p. 1222-1245, 2002.

KLEIN, L.; ALMEIDA, L. B. A Influência dos Fatores Contingenciais na Adoção de Práticas de Contabilidade Gerencial Nas Indústrias Paranaenses. Revista Universo Contábil, v. 13, n. 3, p. 90-119, 2017.

LEONE, N. M. C. P. G. A dimensão física das pequenas e médias empresas (P.M.E's): à procura de um critério homogeneizador. RAE - Revista de Administração de Empresas, v. 31, n. 2, p. 53-59, 1991.

LOFSTEN, H.; LINDELOF, P. Environmental hostility, strategic orientation and the importance of management accounting an empirical analysis of new technology-based firms. Technovation, v. 25, n. 7, p. 725-738, 2005.

MALTEMPI, M. M. Sistemas de medição desempenho organizacional: uma análise comparativa das ferramentas PRISM, PYRAMID e BSC. Revista universitas, n. 13, pág. 107-120, 2014.

MARQUES, K. C. M; SOUZA, R. P. Pontos críticos da abordagem da contingência nos estudos da Contabilidade gerencial. In: CONGRESSO BRASILEIRO DE CUSTOS, 17, 2010, Belo Horizonte. Anais eletrônicos ... Belo Horizonte: CBC, 2010.

MARQUEZAN, L. H. F.; DIEHL, C. A.; ALBERTON, J. R. Indicadores não financeiros de Avaliação de desempenho: análise de conteúdo em relatórios anuais digitais. Revista Contabilidade, Gestão e Governança, v. 16, n. 2, p. 46-61, mar./ago. 2013.

MELNYK, S. A.; STEWART, D. M.; SWINK, M. Metrics and performance measurement in operations management: dealing with the metrics maze. Journal of Operations Management, v. 22, n. 3, pág. 209-218, 2004.

MONTENEGRO, F. R. M. S.; CALLADO, A. L. C. Fatores contingenciais e o uso de indicadores de desempenho: um estudo no setor de confecção do vestuário de João Pessoa / PB. RGO - Revista Gestão Organizacional, v. 12, n. 1, p. 73-91, 2019.

MOREIRA, E. Proposta de uma sistemática para o alinhamento das ações operacionais aos objetivos estratégicos, em uma gestão orientada por indicadores de desempenho. 2002, $204 \mathrm{f}$. Tese (Doutorado em Engenharia de Produção) - Programa de Pós-Graduação em Engenharia de Produção, Centro Tecnológico, Universidade Federal de Santa Catarina, Florianópolis: 2002.

NAKAMURA, W. T.; MINETA, R. K. N. Identificação dos fatores que induzem ao uso do Balanced Scorecard como instrumento de gestão estratégica. In: ENCONTRO DA ASSOCIAÇÃO NACIONAL DOS PROGRAMAS DE PÓSGRADUAÇÃO EM ADMINISTRAÇÃO, 25, 2001, Campinas. Anais ... São Paulo: ANPAD, 2001.

OTLEY, D. The contingency theory of management accounting and control: 1980-2014. Management Accounting Research, v. 31, p. 45-62, 2016.

PARIZI, C. C.; NAAS, I. A.; GARCIA, S. Fatores que influenciam na produtividade do trabalhador da construção civil. Revista Spacios, v. 38, n. 19, p. 26-33, 2017. 
PEREIRA, J. R.; REZENDE, L. B. O.; ANDALÉCIO, A. M. L.; SOUSA, C. V.; MATOS, E. B. A gestão do conhecimento em uma instituição de ensino privada. Revista Perspectivas em Gestão \& conhecimento, v. 6, n. 2, p. 113-133, 2016.

PRODANOV, C. C.; FREITAS, E. C. Metodologia do Trabalho Científico [recurso eletrônico]: métodos e técnicas da pesquisa e do trabalho acadêmico. 2. Ed. Novo Hamburgo: Feevale, 2013.

QUESADO, P. R.; GUZMÁN, B. A.; RODRIGUES, L. L. Factores determinantes de la implementación del Cuadro de Mando Integral en Portugal: evidencia empírica en organizaciones públicas y privadas. Revista Brasileira de Gestão de Negócios, v. 16, n. 51, p. 199-222, 2014.

RELVAS, T. R. S. Relação entre mensuração contábil e a mensuração científica. In: Congresso Brasileiro de Contabilidade, 18, 2008, Gramado. Anais ... Rio Grande do Sul: CFC, 2008.

RIBEIRO, M. G. C.; MACEDO, M. A. S.; MARQUES, J. A. V. C. Análise da relevância de indicadores financeiros e não financeiros na avaliação de desempenho organizacional: um estudo exploratório no setor brasileiro de distribuição de energia elétrica. Revista de Contabilidade e Organizações, v. 6, n. 15, p. 60-79, 2012.

SANTOS, F. O.; JESUS, S. R. P.; SOUZA, W. A. R.; CAVALCANTE, T. S. B. Avaliação do sistema de controle gerencial sob a influência de fatores contingenciais: estudo de caso em um grupo econômico. Revista de Contabilidade e Controladoria, v. 8, n.2, p. 23-48, 2016.

SANTOS, M. M. O.; QUEL, L. F.; VIEIRA, A. M.; ROSINI, A. M. Indicadores de Desempenho e Engajamento Profissional em Organizações Inovadoras. Revista de Gestão e Secretariado, v. 10, n. 1, p. 192-212, 2019.

SEBRAE - SERVIÇO BRASILEIRO DE APOIO ÀS MICRO E PEQUENAS EMPRESAS. Anuário do trabalho na micro e pequena empresa. 6. ed. Brasília: DIEESE, 2013.

SINDUSCON/PE - Sindicato da Indústria da Construção Civil no Estado de Pernambuco (2018). Disponível em:< http://www.sindusconpe.com.br/associados >. Acesso em: 20 jan. 2018.

SIQUEIRA, K. P. S. Uma investigação acerca do uso de indicadores de desempenho em empreendimentos hoteleiros situados na Região Metropolitana de Recife, 2014. 94 f. Dissertação de Mestrado (Ciências Contábeis) - Universidade Federal de Pernambuco, Centro de Ciências Sociais Aplicadas. Recife, 2014.

SILVA, A. R.; CALlADO, A. A. C.; CALLADO, A. L. C. Análise das relações entre o uso de indicadores de desempenho e fatores contingenciais de empresas de empresas do setor da construção civil. In: CONGRESSO BRASILEIRO DE CUSTOS, 23, 2016, Porto de Galinhas. Anais ... Pernambuco: CBC, 2016.

SILVA, A. R.; CALLADO, A. L. C. Relações entre fatores contingenciais de empresas do setor da construção civil e a importância atribuída a indicadores de desempenho. Revista Capital Científico, v. 16, n. 1, p. 112-129, 2018a.

SILVA, A. R.; CALLADO, A. L. C. Aderência de indicadores de desempenho associados às perspectivas do Balanced Scorecard no setor da construção civil do município de João Pessoa (PB). REUNIR: Revista de Administração, Ciências Contábeis e Sustentabilidade, v. 8, n. 2, p. 23-34, 2018b. 
SOROOSHIAN, S.; AZIZ, N. F.; AHMAD, A.; JUBIDIN, S. N.; MUSTAPHA, N. M. Review on performance measurement systems. Mediterranean Journal of Social Sciences, v. 7, n. 1, p. 123-132, jan. 2016.

TEZZA, R.; BORNIA, A. C.; VEY, I. H. Sistemas de medição de desempenho: uma revisão e classificação da literatura. Revista Gestão \& Produção, v. 17, n. 1, p. 75-93, jan./mar. 2010.

VENKATRAMAN, N.; RAMANUJAM, V. Measurement of business performance in strategic research: a comparison of approaches. Academic Management Review, v. 11, p. 801-814, 1986.

WAGGONER, D. B.; NEELY, A. D.; KENNERLEY, M. P. The forces that shape organisational performance measurement systems: An interdisciplinary review. International Journal of Production Economics, v. 60-61, n. 1, p. 53-60, abr. 1999.

WERNKE, R.; JUNGES, I. Níveis de utilização e importância atribuídos aos indicadores não financeiros por empresas da região sul de Santa Catarina. Revista Contemporânea de Contabilidade, v. 14, n. 03, p. 55-87, set./dez. 2017.

Recebido em: 4-5-2019

Aprovado em: 17-12-2020

Avaliado pelo sistema double blind review.

Disponível em http://mjs.metodista.br/index.php/roc 